\title{
Retrieving Snowpack Properties and Accumulation Estimates From a Combination of SAR and Scatterometer Measurements
}

\author{
Gerit Rotschky, Wolfgang Rack, Member, IEEE, Wolfgang Dierking, and Hans Oerter
}

\begin{abstract}
This study combines two satellite radar techniques, low-resolution $\mathrm{C}$-/Ku-band scatterometer and high-resolution C-band synthetic aperture radar (SAR) for glaciological studies, in particular mass-balance estimations. Three parameters expressing the mean backscattering and its dependency on azimuth and incidence angle are used to describe and classify the Antarctic ice sheets backscattering behavior. Simple linear regression analyses are carried out between ground truth accumulation data and the SAR backscattering coefficient along continuous profile lines. From this we parameterize the accumulation rate separately for certain snow pack regimes. We find that SAR data can be used to map mass-balance changes, however only within limited areas. Applying this method therefore generally requires accurate ground truth for regional calibration together with additional information regarding mean air temperature or elevation. This investigation focuses on the area of Dronning Maud Land, Antarctica. We present the first high-resolution accumulation map based on SAR data for the surrounding area of the EPICA deep ice core drilling site Kohnen, which is compared to reliable ground truth records as well as to a surface-mass-balance map interpolated from these at low resolution.
\end{abstract}

Index Terms-Antarctica, mass balance, satellite radar, snowpack properties.

\section{INTRODUCTION}

$\mathbf{T}$ HE knowledge of Antarctic ice mass balance and its temporal variations is at present still insufficient for determining the ice sheets contribution to global sea level rise with high accuracy [40]. Ice-sheet modeling is uncertain due to missing small-scale data for most regions. Recently, traditional methods of accumulation measurements, i.e., stake line readings, or point sampling by snow pits and firn core drilling have been supplemented by ice-penetrating radar (IPR) studies capable of retrieving mass-balance information along continuous profile lines [12], [31], [33], [38], [39], [41]. Despite these efforts, there is still a lack of surface-mass-balance data at a resolution that is mapping the high spatial variability of accumulation rate. The latter was found to reach up to $50 \%$ over distances of a few kilometers [41], even under the homogenous meteorological and topographic conditions of Dronning Maud Land's (DML) plateau region. Therefore, it is questionable how representative single point measurements are for large-scale accumulation compilations, considering their coarse sampling

Manuscript received April 27, 2005; revised November 3, 2005.

The authors are with the Alfred Wegener Institute for Polar and Marine Research, 27515 Bremerhaven, Germany (e-mail: grotschky@ awi-bremerhaven.de; wrack@awi-bremerhaven.de; wdierking@awi-bremerhaven.de; hoerter@awi-bremerhaven.de).

Digital Object Identifier 10.1109/TGRS.2005.862524 scheme. The reconstruction of paleoclimate records from ice cores relies on detailed information of their accumulation history. If the drilling takes place on moving ice, the long-term accumulation variability detected in an ice core arises as a combination of true climatical changes as well as movement of the core-hole site through a given surface-mass-balance pattern upstream [20], [28], [44]. Since the latter depends on irregular surface undulations on a kilometer scale [20], [41] a spatial resolution of accumulation data better than $1 \mathrm{~km}$ would be desirable in order to be able to identify and remove the effects of local topography and ice flow on accumulation time series. At present maps at this resolution are not available.

Overcoming these uncertainties and recovering spatiotemporal ice sheet volume variations have become a major goal of current spaceborne Earth observation methods, in the first instance carried out by passive [5], [55] and active microwave instruments [6], [8], [11], [30], [47], [48], [53]. Although much effort has been done to assess the principles of microwave interaction with snow and ice, they are not yet completely understood in all their complexity [1]. In general, microwave signatures depend on the angular distribution of energy due to scattering at the surface and in the firn pack as well as on absorption losses. Within the dry snow zone, the accumulation rate is seen as a key factor that determines the morphological structure of the snow pack. Spatiotemporal variations in snow deposition are therefore expected to have a major impact on the radar backscattering. The capability of microwave remote sensing for estimating snow accumulation has been recognized as a result of the reported inverse correlation between the backscattering coefficient $\sigma^{0}$ and accumulation rate [3], [8], [11], [23], [26], [30].

For the case of dry snow, the surface scattering in $\mathrm{C}$ - and $\mathrm{Ku}-$ band can be neglected [10], [13]. The volume scattering is dominated by Rayleigh scattering, although Mie Scattering may play a role in Ku-band for a grain size larger than $5 \mathrm{~mm}$ [50]. Taking into account the typical volume densities of the snow pack, permittivity and extinction properties are to be calculated based on the dense medium transfer theory [10]. In order to obtain more realistic estimates of the backscattering of deep dry snow packs, density-stratified layers have to be considered in model calculations [3], [52]. Flach et al. [9] applied a least squares inversion technique to derive snowpack properties, such as accumulation for the dry snow zone of Greenland. Their method relies on simulating the variations of the microwave intensity due to seasonal changes of the snowpack. However, the absolute magnitude of backscattering intensity could not be reproduced by the model.

We aim at extending previous studies in order to classify regions with a similar nature of backscattering over the 


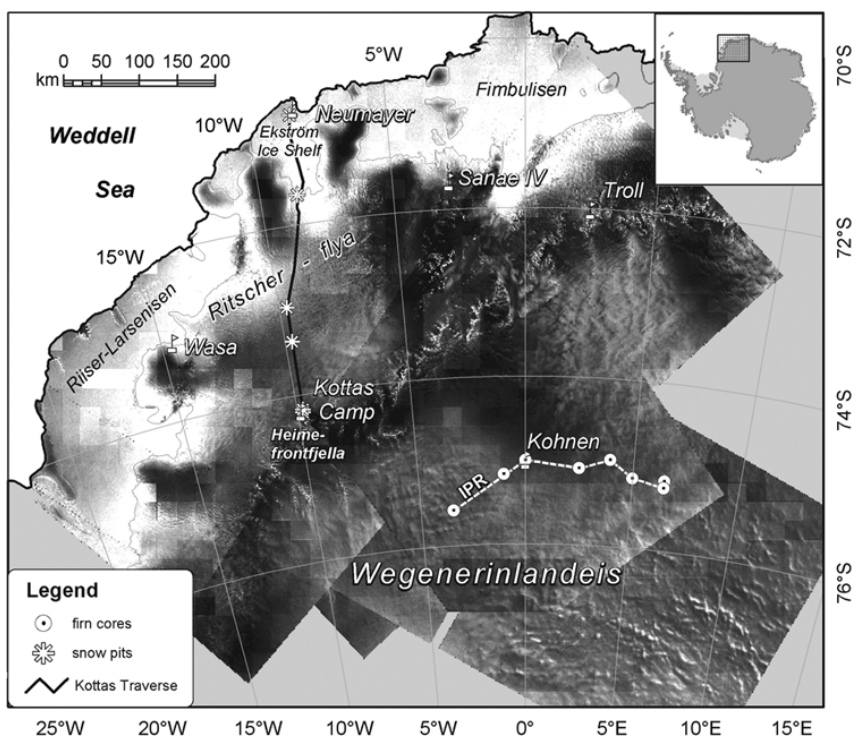

Fig. 1. Envisat ASAR mosaic of study region, Dronning Maud Land, showing several AWI snow pit and firn core sampling sites, as well as routes of stake readings (black line) and IPR (white striped line) providing ground truth data on accumulation rates. The ASAR images have been normalized to a single incidence angle of $35^{\circ}$ and an azimuth angle of maximum backscattering for each pixel respectively as described in the text.

Antarctic ice sheet. Our attempt is the combination of overlapping scatterometer images at different frequencies in order to define snow pack classes by three parameters. Although the spatial resolution of scatterometers is low, they provide valuable information regarding backscattering at high temporal and geometrical resolution, which can be linked to snow pack properties, i.e., characteristics like snow grain size, density, subsurface layering, water content, or surface roughness [8], [19], [21], [23], [25]-[27], [37], [42], [54]. Within defined snow regimes we investigated the relationship between synthetic aperture radar (SAR) backscattering and snow pack properties, in the first place using accumulation rates derived by stake readings and IPR. This was conducted for two traverse routes: 1) leading from the German Neumayer station (70³9'S, $\left.08^{\circ} 15^{\prime} \mathrm{W}\right)$ located on the Ekström Ice Shelf to the German

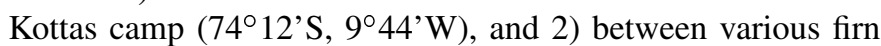
core locations on the high plateau of DML passing the Euopean Project of Ice Coring (EPICA) drilling camp Kohnen $\left(75^{\circ} \mathrm{S}\right.$, $\left.0^{\circ}\right)$ (Fig. 1).

\section{DATA AND METHODS}

\section{A. Scatterometer Data and Image Reconstruction}

We used VV-polarized 5.3-GHz (C-band) Escat and overlapping 14-GHz (Ku-band) Nscat data acquired during a full repeat cycle in winter 1997 to characterize the backscattering properties of the ice sheet, expressed by the normalized radar cross section $\sigma^{0}$. During this time, the snow pack is completely frozen and holds stable conditions [8]. Small variations due to wind drift were not considered. Both sensors have been reported to be steady in calibration, precise enough for our purposes [24], [49].

The Escat sensor (ERS-2 Active Microwave Instrument in wind scatterometer mode) measures the surface backscattering
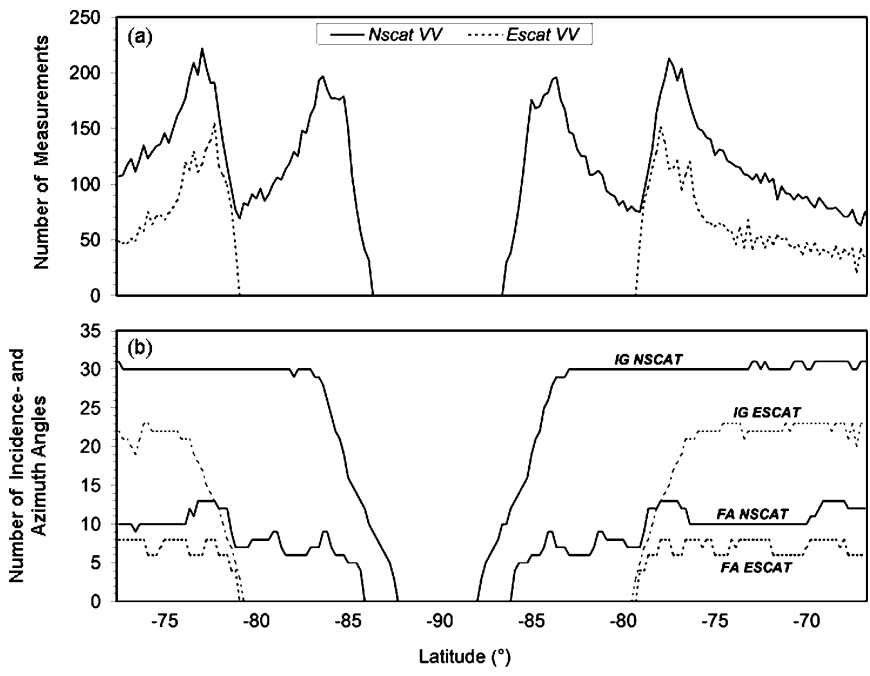

Fig. 2. Number of (a) $\sigma_{\text {mean }}^{0}$ measurements and (b) covered incidence angles and azimuth-angle bins included in each image grid cell following the $90^{\circ} \mathrm{E}$ and $90^{\circ} \mathrm{W}$ meridians across Antarctica.

with three right-looking antennas over a single 500-km-wide swath to a southernmost extent of $79.5^{\circ} \mathrm{S}$, and with a nominal resolution of $50 \mathrm{~km} \mathrm{[2].} \mathrm{The} \mathrm{Nscat} \mathrm{instrument} \mathrm{onboard} \mathrm{the}$ Japanese Advanced Earth Observation Satellite (ADEOS-1) operated with two 600-km-wide swaths on both sides of the satellite track, separated by a 400-km gap. Six vertical (VV) and two horizontal $(\mathrm{HH})$ polarized antenna beams cover Antarctica to within $1.2^{\circ}$ of the pole. Despite the short mission duration (September 1996 to July 1997), the Nscat time series enable more detailed studies of electromagnetic scattering properties, due to its higher spatial resolution of $25 \mathrm{~km}$ and broader azimuth and incidence angle coverage.

In order to obtain a complete set of possible viewing angles for a particular footprint of each sensor, the acquisition time intervals include a 35-day period for Escat (May 28 to June 30, 1997) and 41-days for Nscat (May 20 to June 30, 1997). Small acquisition gaps for Nscat were neglected. For the analysis, the single beam measurements were gridded at a resolution of $25 \mathrm{~km}$, using a polar stereographic projection with the true scale set to $71^{\circ} \mathrm{S}$ for minimizing distortions within the DML study region. At each grid cell all observations within the imaging period are summed and then averaged in order to obtain a mean backscattering response.

Following [36] and [43], three slightly modified parameters have been calculated for each grid cell in order to characterize the backscattering: the mean backscattering coefficient $\sigma_{\text {mean }}^{0}$ (decibels) within the incidence-angle range of $30^{\circ}$ to $40^{\circ}$ over all viewing angles $\alpha$, the factor of anisotropy (FA), and the incidence angle gradient (decibels per degree), in the following named IG. The latter was evaluated by applying a first-order least square fit over all $\sigma^{0}$ measurements within the incidence angle range of $20^{\circ} \leq \theta \leq 50^{\circ}$, for which $\sigma^{0}$ (decibels) was found to decrease almost linearly [3], [23], [26]. FA describes the azimuthal modulation of $\sigma^{0}$ and is calculated according to

$$
\begin{aligned}
& \mathrm{FA}=\frac{\sum_{j=1}^{18}\left|\sigma_{\Delta \alpha_{j}, \text { mean }}^{0}-\sigma_{\text {mean }}^{0}\right|}{\sigma_{\text {mean }}^{0}} \\
& \alpha_{j}=20 \cdot j, \quad \Delta \alpha_{j-1}, \ldots, \alpha_{j}
\end{aligned}
$$



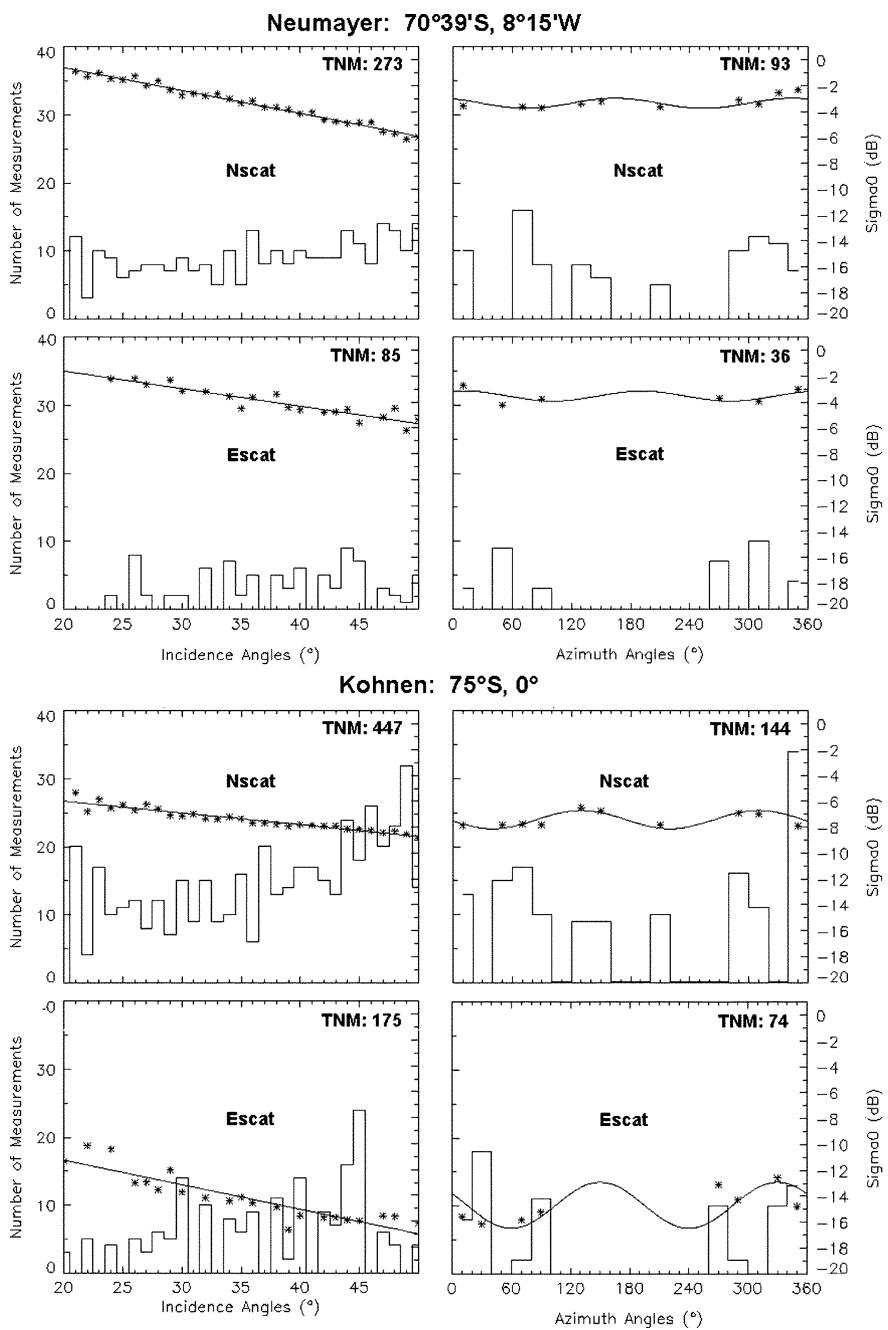

Fig. 3. $\sigma^{0}$ and number of measurements that entered computation of IG (left side) and FA as well as $\sigma_{\text {mean }}^{0}$ (right side) as function of incidence and azimuth angles for two sample image pixels $\left(25 \times 25 \mathrm{~km}^{2}\right)$, corresponding to the location of Neumayer and Kohnen station. The total number of measurements (TNM) is given at the upper right corners.

where $\Delta \alpha_{j}$ stands for 18 azimuth-angle bins in $20^{\circ}$ steps. This way we obtained three images for each sensor, mapping the spatial distribution of backscattering characteristics. The number of measurements which enter the computation is represented in Fig. 2, following a meridian across the Antarctic continent. Variations occur according to the satellite-swath geometry, e.g., for calculating $\sigma_{\text {mean }}^{0}$ the number of records ranges from 19-227 for Nscat and from 12-180 for Escat, respectively. Toward the imaging limits the number of covered incidence angles decreases, e.g., for Escat, south of $78.8^{\circ} \mathrm{S}$ no incidence angles higher than $30^{\circ}$ are available. Estimating Escat FA becomes critical at certain locations, because of the limited azimuth viewing geometry. At no point a number of eight out of 18 possible azimuth-angle bins is exceeded for this sensor. Two sample locations, Neumayer station and Kohnen camp, give an impression on data density and distribution over the viewing angle ranges (Fig. 3).

\section{B. ENVISAT ASAR Normalization}

Envisat Advanced Synthetic Aperture Radar (ASAR) VV-Pol wideswath data acquired in March 2004 were calibrated and gridded to a 100 - and 250-m raster, respectively. Geocoding was done using the RAMP digital elevation model [22]. The speckle noise was reduced by applying a $3 \times 3$ running mean. The locational accuracy of the geocoded product is estimated to be within $100 \mathrm{~m}$ according to ground truth data. ASAR data were normalized to a uniform incidence angle $\left(35^{\circ}\right)$ and azimuth angle $\left(0^{\circ}\right)$, using our Escat backscattering parameters IG and $\sigma_{\Delta \alpha j}^{0}$. This approach is based on the assumption that the dependence of backscattering on viewing geometry as observed for larger areas from satellite is comparable to the small-scale situation, which is justified by ground-based scatterometer measurements for IG in DML [42]. We assume that the same is valid for FA. We carried out a pixel to pixel comparison of overlapping ASAR tracks covering homogenous areas near Kohnen station. By this process we found the local variations of IG to be in the order of $0.1 \mathrm{~dB} \cdot \mathrm{deg}^{-1}$, inducing a normalization error small enough to be of minor significance in this area. We note that further field data are necessary to fully evaluate the uncertainty due to the use of low-resolution data in high-resolution applications. Normalization to an incidence angle of $35^{\circ}$ for an entire image was carried out according to

$$
\sigma^{0}\left(35^{\circ}\right)_{0^{\circ} \leq \phi \leq 360^{\circ}}=\sigma^{0}(\theta)+\operatorname{IG}\left(35^{\circ}-\theta\right) .
$$

Parameter $\theta$ describes the local incidence angle between surface normal and look vector at each image pixel. Variations of $\sigma^{0}$ versus azimuth angle are determined by a nonlinear least square function of the form

$$
\sigma^{0}(\phi)=A+B \cos (2(\phi-C))
$$

where $\phi$ stands for the azimuth-look angle measured from north, and the coefficients $A, B$, and $C$ express the backscattering and its anisotropy. The function given in (3) was fitted to our Escat data within the incidence angle range of $30^{\circ}$ to $40^{\circ}$, averaged for areas of $25 \times 25 \mathrm{~km}^{2}$ over the entire imaging period.

\section{Ground Truth Data}

Various ground truth data collected in DML in the framework of the EPICA pre-site survey are available for the period 1996 to 1999. The field studies have been continued and extended in the years after. Here we use data on the ice sheets annual surfacemass balance and snow layer structure based on snow pit studies, stake line readings, and IPR, making available an excellent basis for correlating accumulation rates with our satellite data.

A line of 675 stakes at 500-m intervals was set up along the Neumayer-Kottas camp traverse route, providing a mass-balance transect of high spatial resolution with annual readings between 1999 and 2001. The stake measurements (in meters) have been converted to accumulation rates (in kilograms per square meter per year) by integration of density profiles, derived from several snow-pit sites along the way (third-order polynomial functions were fitted to density data for each site covering the upper 1.4-2 $\mathrm{m}$ of the snowpack). Together with the ice, the stakes are moving toward the coast with an average speed of $52.4 \mathrm{~m} /$ year, increasing to $168 \mathrm{~m} /$ year beyond the grounding line on the Ekström Ice Shelf. Because of these position changes with time, the annual accumulation records were assigned to fixed geographic locations along the transect with 500-m spacing by linear interpolation. On the plateau around 
(a)

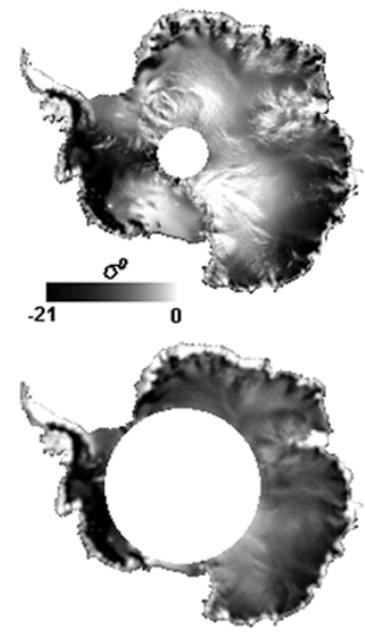

(d) (b)

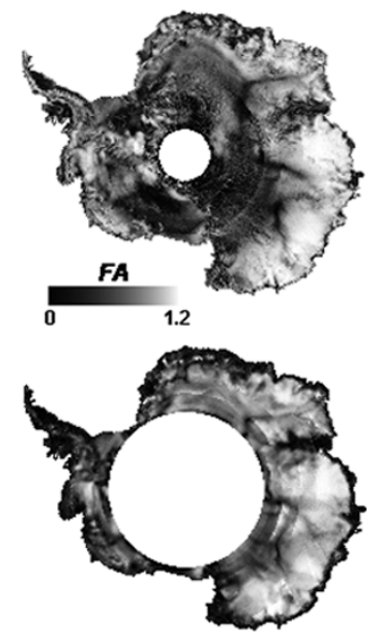

(e)

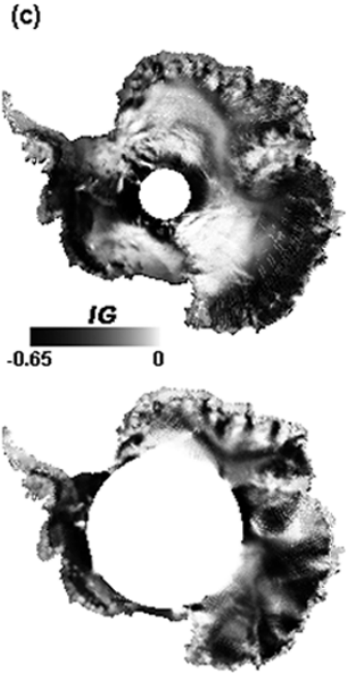

(f)

Fig. 4. Parameter images derived from VV polarized scatterometer images. (a) Nscat $\sigma_{\text {mea }}^{0}$

(b) Nscat FA. (c) Nscat IG. (d) Escat $\sigma_{\text {mean }}^{0}$ (e) Escat FA. (f) Escat IG.

TABLE I

CORRELATION COEFFICIENTS BETWEEN DERIVED PARAMETERS

\begin{tabular}{lc|lrr}
\hline \hline \multicolumn{2}{l|}{ Nscat / Escat } & & Nscat & Escat \\
\hline$\sigma_{\text {mean }}^{0}$ & 0.84 & $\sigma_{\text {mean }}^{0} / F A$ & -0.51 & -0.40 \\
$F A$ & 0.72 & $\sigma_{\text {mean }}^{0} / I G$ & 0.78 & 0.45 \\
$I G$ & 0.48 & $F A / I G$ & -0.56 & -0.15 \\
\hline \hline
\end{tabular}

the Kohnen station, an IPR-derived surface mass-balance profile serves as ground truth for comparison, covering a time span of 182 and 184 years, respectively [41].

\section{RESULTS}

\section{A. Frequency-Dependent Differences in Backscattering}

The spatial patterns in our $\sigma_{\text {mean }}^{0}, \mathrm{FA}$, and IG parameter maps (Fig. 4) reflect differences in snow morphology, i.e., surface roughness, density, layering, and/or grain size [36]. This is due to variable conditions in local climate, wind, and accumulation rate, which are governed by geographic location, slope, elevation, and orographic effects as well as surface undulations. Artefacts visible within the FA images are caused by sudden changes in the number of covered azimuth-angles subjected to the orbit geometry [see also Fig. 2(b)], e.g., for Nscat a drop from 13 to only seven covered azimuth-angle bins causes a concentric feature at $79^{\circ} \mathrm{S}$. We did not consider these distortions to be a crucial factor for the further analysis, since general changes in backscattering are still evident and no distortions are visible within the classification results, presented below.

Despite differences in spatial resolution and frequency between both sensors, the results display the same general features for all three parameters. They are consistent with previous findings [25], [26], [36], [43]. In Table I we list the correlation coefficients between the $\mathrm{C}$ - and $\mathrm{Ku}$-band results as well as for all parameters to each other, separated for each sensor. The low correlation for IG between both sensors is likely due to differences in penetration depth within the dry snow zone. In general Escat-derived parameters are less correlated to each other than those of Nscat, which could partly be a consequence

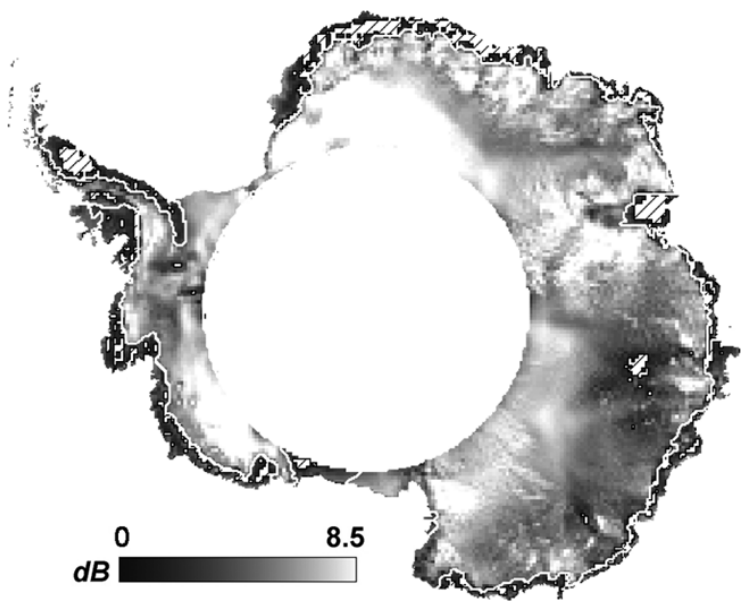

Fig. 5. Frequency difference image Nscat minus Escat including the percolation zone boundary as defined in the text. Areas of $\sigma_{\mathrm{ku}}^{0}<\sigma_{c}^{0}$ are marked by white striped signatures.

of the lower spatial resolution and azimuth coverage. A significant correspondence is observed for the Nscat-derived parameters $\sigma_{\text {mean }}^{0}$ and IG. Field measurements in C-band show that low backscattering of a homogenous snow pack is often combined with high IG and vice versa [42]. In spite of this fact we used all parameters as input for a classification as described below, since the information used is not fully redundant.

Large areas of extremely high backscattering in the interior regions of east Antarctica can be observed in the Nscat result only [Fig. 4(a)]. Consequently, here we find the strongest frequency differences in backscattering, reaching values of up to $8.5 \mathrm{~dB}$ (Fig. 5). Interestingly also the ice divides take shape clearly as regions of high $\sigma_{\text {mean }}^{0}$ differences with $\sigma_{c}^{0}<\sigma_{\mathrm{ku}}^{0}$ by $4-6 \mathrm{~dB}$. Backscattering differences are small within regions affected by strong katabatic air flow, as well as within the percolation zone. In agreement with observations in Greenland [25], we find large areas with $\sigma_{\mathrm{ku}}^{0}<\sigma_{C}^{0}$ within the percolation zone (also marked in Fig. 5). During our imaging interval Ku-band is probably mainly reflected by a relatively homogenous winter snow layer, whereas for C-band buried layers of older firn and 
(a)
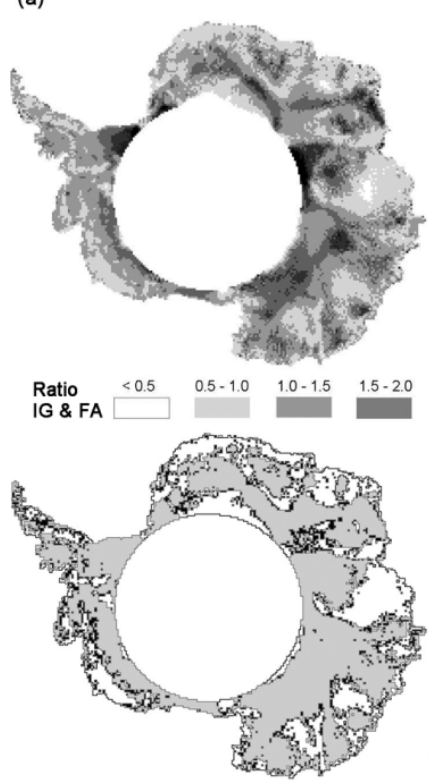

(b)
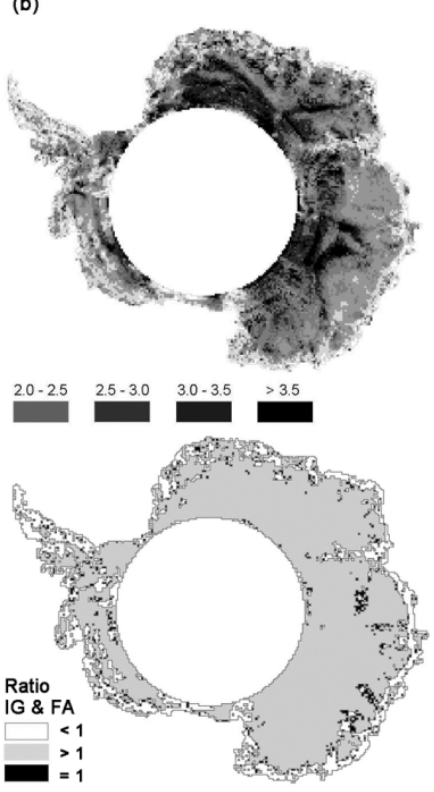

Fig. 6. (a) Ratio IG Escat/IG Nscat and (b) Ratio FA Escat/FA Nscat. Values $<1$ indicate areas with higher dependence on viewing geometry (incidence and azimuth angles) for the smaller $\mathrm{Ku}$-band wavelength.

melt features act as strong scatterers. In opposite, within the dry snow zone, the backscattering level of Escat is in general lower compared to the Nscat data, as observed as well by [3], [26], and [42]. An exception from this is a smaller region in Queen Mary Land $\left(100^{\circ} \mathrm{E}\right)$, exhibiting at the same time high values for FA.

In accordance to [8] for Greenland we defined the dry snow zone boundary as mapped in Fig. 5 by using a frequency-difference threshold of $\sigma_{\mathrm{ku}}^{0}-\sigma_{c}^{0}>1.8 \mathrm{~dB}$. In addition we utilized the fact that low values for FA are another specific feature of areas affected by summer melt. Therefore, we used a value of Escat FA $<0.3$ for further delimitation of the percolation zone. Remaining scattered areas which have been misselected using this approach were removed manually.

Smooth IG is observed at the high-elevation areas of dense stratification on the East Antarctic Plateau. Large negative values of this parameter are found within the dry snow zone if the accumulation rate is relatively high. By looking at the lower image of Fig. 6(a), it becomes evident that IG Nscat is steeper than IG Escat within regions where effective scattering layers close to the surface can be expected reducing the penetration depth especially for the higher frequency. Those are: 1) the katabatic wind regions of east Antarctica due to wind glazed surfaces and roughness features, such as sastrugi; 2) the percolation zone (buried ice lenses, pipes, and layers); as well as 3 ) the high-elevation plateau regions of intense backscattering, for which large snow crystals within the upper snow pack can be assumed [45]. In opposite, for regions missing such features IG Escat is generally steeper then IG Nscat, with biggest differences for flat regions, namely along the crest of the ice divides, as well as the Ronne ice shelf. Our findings agree with field studies carried out by [42], who found the incidence angle dependence increasing together with penetration depth. Drinkwater et al. [8] related a steeper gradient of $\sigma^{0}$ versus incidence angle with increasing accumulation rates, accompanied with a reduction of grain size and hence reduced backscattering.

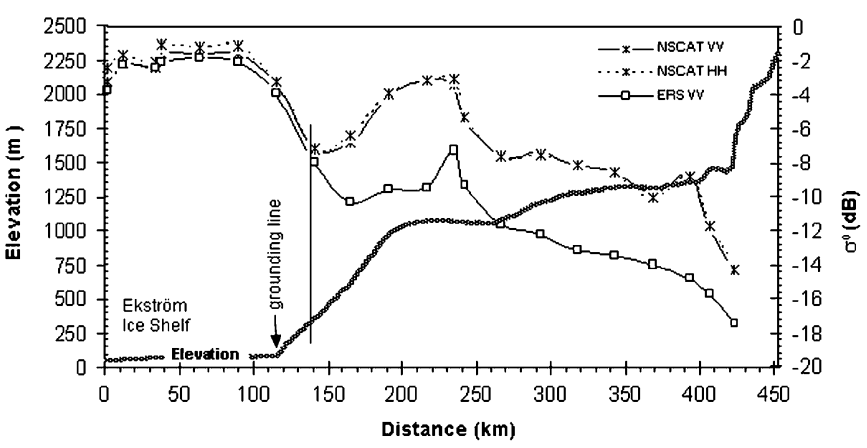

Fig. 7. $\sigma_{\text {mean }}^{0}$ and elevation change along a traverse route from Neumayer station to Kottas camp. Topographic information was taken from RAMP digital elevation model [22].

Patterns of increased FA are generally accompanied by a steeper IG for both sensors, with the exclusion of Princess Elizabeth Land $\left(70^{\circ}\right.$ to $\left.90^{\circ} \mathrm{E}\right)$ for Escat. Differences in FA between both sensors are strongest in areas of largest penetration depth differences linked with very low accumulation rates. Regions of FANscat $>$ FA Escat are restricted almost exclusively to the percolation zone near the coast [see lower image of Fig. 6(b)].

Fig. 7 shows a comparison of $\sigma_{\mathrm{ku}}^{0}$ to $\sigma_{\mathrm{c}}^{0}$ along a transect from Neumayer station on the Ekström Ice Shelf to Kottas camp. From the grounding line at a distance of $120 \mathrm{~km}$ south of Neumayer, the ice sheet is rising in steps from the flat ice-shelf area to an elevation of about $2000 \mathrm{~m}$ a.s.l. The boundary between the coastal percolation zone to the dry snow zone is marked by the sudden divergence of our scatterometer profiles. Within regions affected by summer melt, buried ice lenses, and hoar layers act as strong scatterers and prevent microwaves from deeper penetration into the snow pack. Further upslope above $400 \mathrm{~m}$ a.s.1., where mean annual air temperatures do not exceed $-10^{\circ} \mathrm{C}[23]$, frequency differences in backscattering response become recognizable, due to differences in penetration depth. The cross-over to dry snow conditions with increasing altitude occurs with a remarkable drop in $\sigma^{0}$ from -2 to $-10 \mathrm{~dB}$ for Escat and to $-7 \mathrm{~dB}$ for Nscat. Within the dry snow zone $\sigma_{\mathrm{ku}}^{0}>\sigma_{\mathrm{c}}^{0}$ is generally observed, but both curves progress parallel, with a differences of up to $6.2 \mathrm{~dB}$. A notable sudden rise in backscattering between $150-250 \mathrm{~km}$ from the starting point can be observed for both wavelengths, but is less pronounced for the longer wave Escat data. This could partly be a consequence of the difference in spatial resolution between both sensors. Furthermore a comparison with accumulation measurements suggests that within this range of our transect a decrease in net mass balance to values as low as $60 \mathrm{~kg} \cdot \mathrm{m}^{-2} \cdot \mathrm{a}^{-1}$ (Section IV-A) might cause changes in grain size and layering in an order that primarily affects the shorter wave Ku-band [8]. The Nscat backscattering is almost independent of polarization which was also observed in Greenland [46], with slight differences in backscattering of up to $0.8 \mathrm{~dB}$ only within the coastal percolation zone.

\section{B. Snow Pack Classification}

We applied a maximum-likelihood classification to our data by combining images of $\sigma_{\text {mean }}^{0}$, IG, and FA. This way regions of comparable backscatter response could be delimited for the Antarctic ice sheet as shown in Fig. 8. As in [36] signature 
(a)

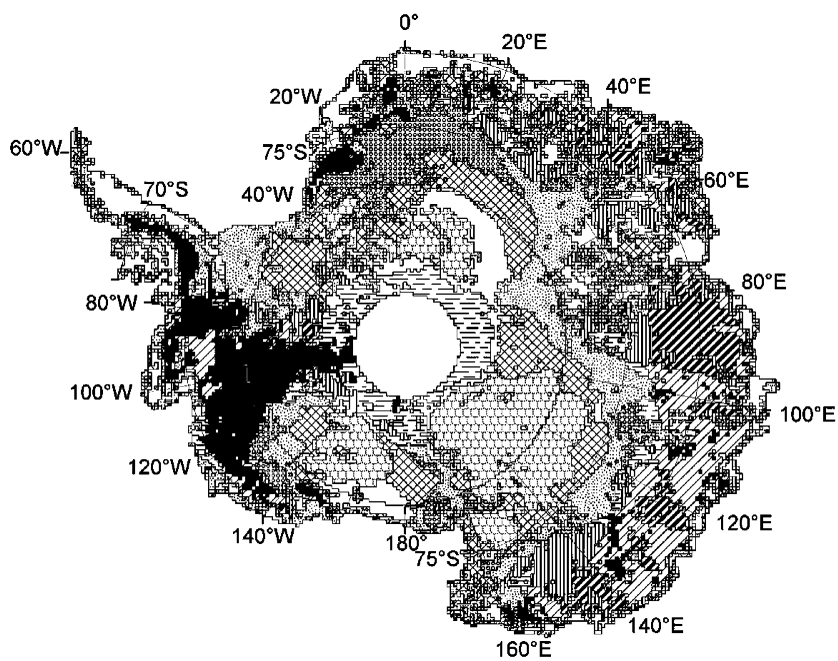

(b)

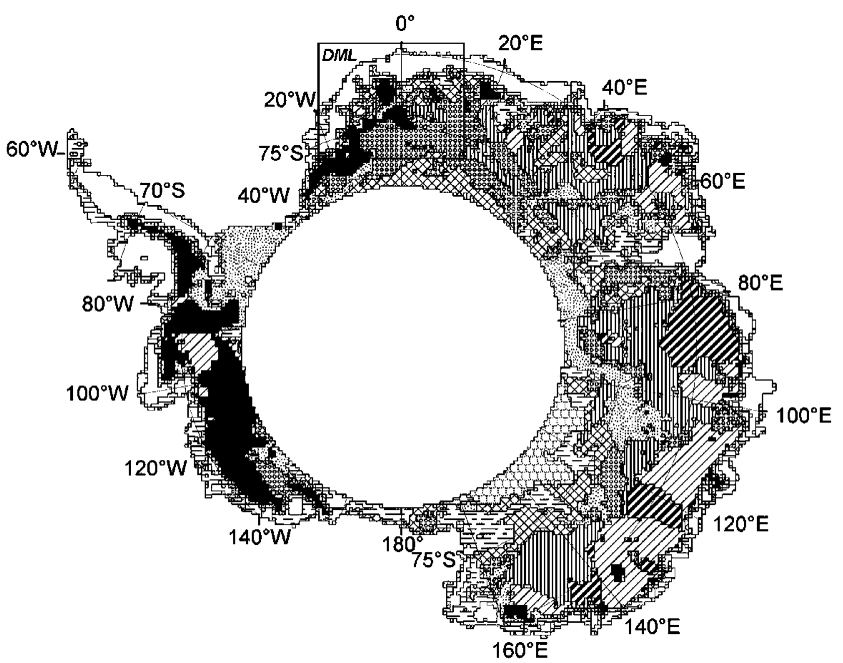

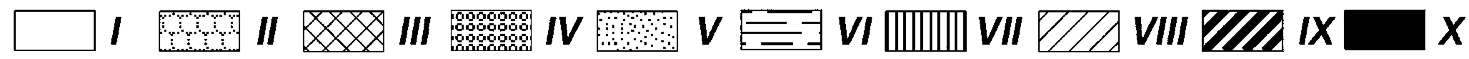

Fig. 8. Maximum-likelihood classification of Antarctic snow pack regimes, resulting from input parameters FA, IG, and $\sigma_{\text {mean }}^{0}$ for (a) Nscat with Escat viewing limits marked by a circle, and (b) Escat. The latter also shows the extent of our DML study region.

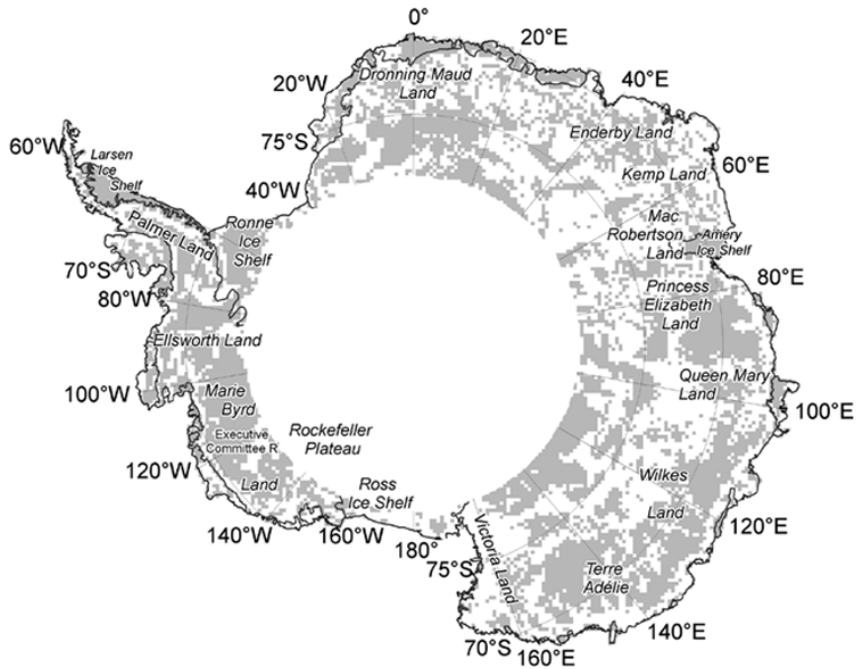

Fig. 9. (Gray) Areas of agreement and (white) disagreement between Escat and Nscat maximum-likelihood classification results.

values for ten classes were forced by training areas with pronounced backscattering behavior, which were identified by first applying unsupervised K-means and isodata classification algorithms. This way we compensated for missing a priori knowledge about the number, position, and extent of existing unique backscattering types.

The results yield a similar general pattern of surface classes for both VV polarized Escat C-band and Nscat Ku-band scatterometer data, in spite of differences in spatial resolution, viewing angle coverage, and geometry between both sensor types. This implies that the dominant backscattering mechanisms are the same for both frequencies. Thus, we consider this simple method as robust for mapping different Antarctic snow facies, even for the less well resolved Escat data. However, the higher resolution Nscat data enable a more detailed discrimination of the single classes shape and extent up to a southern limit of $86^{\circ} \mathrm{S}$. Fig. 9 maps areas that are classified as the same
TABLE II

MAXIMUM-LIKELIHOOD CLUSTER MEANS

\begin{tabular}{lllllll}
\hline \hline & \multicolumn{6}{c}{ Nscat } \\
\hline Class & $\boldsymbol{\sigma}_{\text {mean }}$ & St. Dev & $\boldsymbol{F A}$ & St. Dev & IG & St. Dev \\
$I$ & -2.68 & 1.05 & 0.12 & 0.05 & -0.16 & 0.02 \\
$I I$ & -1.68 & 0.82 & 0.07 & 0.03 & -0.11 & 0.01 \\
$I I I$ & -4.30 & 0.68 & 0.09 & 0.03 & -0.14 & 0.02 \\
$I V$ & -6.35 & 1.23 & 0.16 & 0.04 & -0.14 & 0.02 \\
$V$ & -6.72 & 1.36 & 0.14 & 0.05 & -0.19 & 0.02 \\
VI & -6.88 & 2.21 & 0.18 & 0.09 & -0.23 & 0.07 \\
VII & -6.93 & 1.29 & 0.34 & 0.06 & -0.22 & 0.05 \\
VIII & -11.88 & 1.54 & 0.39 & 0.12 & -0.25 & 0.04 \\
$I X$ & -9.36 & 1.66 & 0.61 & 0.09 & -0.23 & 0.03 \\
$X$ & -12.92 & 1.62 & 0.17 & 0.07 & -0.26 & 0.08 \\
\hline
\end{tabular}

Escat

\begin{tabular}{lllllll}
\hline Class & $\boldsymbol{\sigma}_{\text {mean }}^{\text {m }}$ & St. Dev & $\boldsymbol{F A}$ & St. Dev & $\boldsymbol{I G}$ & St. Dev \\
$I$ & -3.23 & 1.59 & 0.10 & 0.05 & -0.15 & 0.03 \\
$I I$ & -6.31 & 0.73 & 0.25 & 0.08 & -0.16 & 0.05 \\
$I I I$ & -9.75 & 1.24 & 0.28 & 0.10 & -0.18 & 0.07 \\
$I V$ & -11.92 & 1.21 & 0.39 & 0.07 & -0.19 & 0.05 \\
$V$ & -11.13 & 1.62 & 0.29 & 0.15 & -0.32 & 0.10 \\
$V I$ & -8.01 & 1.28 & 0.13 & 0.05 & -0.19 & 0.05 \\
VII & -10.70 & 1.10 & 0.59 & 0.10 & -0.24 & 0.06 \\
VIII & -14.27 & 1.34 & 0.55 & 0.11 & -0.33 & 0.06 \\
$I X$ & -12.91 & 1.70 & 0.85 & 0.13 & -0.17 & 0.04 \\
$X$ & -17.34 & 2.01 & 0.25 & 0.09 & -0.30 & 0.08 \\
\hline \hline
\end{tabular}

type by both sensors, making up $48.4 \%$ of the area common to both sensors.

Differences in the allocation of pixels to a certain class concern regions where the crossover from one surface type to another is not very distinct, expressed by similar cluster means for all three parameters as shown in Table II. Those are the low-accumulation dry snow areas with homogenous snow pack morphology, represented by classes III-VII. Here it was difficult to decide for training areas that we assumed to be most representative for both frequencies. Nearly no correspondence was found for class VI for which only $10 \%$ of all pixels are in common 
TABLE III

CHARACTERISTICS OF SNOW PACK ClASSES

\begin{tabular}{|c|c|c|c|c|c|}
\hline \multirow{3}{*}{$\begin{array}{l}\text { Class } \\
\text { Total } \\
\text { Area }\end{array}$} & \multicolumn{3}{|c|}{ Percentage of surface } & \multirow{3}{*}{$\begin{array}{l}\text { Accum. } \\
\mathrm{kg} \mathrm{m}^{-2} \mathrm{a}^{-1}\end{array}$} & \multirow[t]{3}{*}{ Typical phys. properties } \\
\hline & Escat & Nscat $^{1}$ & Nscat & & \\
\hline & \multicolumn{2}{|c|}{$\begin{array}{c}95 \times 10^{5} \\
{\left[\mathrm{~km}^{2}\right]} \\
\end{array}$} & $\begin{array}{c}135 \times 10^{5} \\
{\left[\mathrm{~km}^{2}\right]} \\
\end{array}$ & & \\
\hline$I$ & 10.14 & 10.45 & 11.40 & $\begin{array}{l}\text { high, in } \\
\text { general } \\
>150\end{array}$ & $\begin{array}{l}\text { percolation zone, highly } \\
\text { metamorphosed, varying } \\
\text { grain sizes, distinct ice } \\
\text { lenses and pipes }\end{array}$ \\
\hline II & 4.31 & 6.07 & 12.12 & $\begin{array}{l}\text { very low, } \\
<50\end{array}$ & $\begin{array}{l}\text { coarse grained, distinct } \\
\text { stratification }\end{array}$ \\
\hline III & 11.85 & 10.30 & 13.16 & & no striking features or only \\
\hline$I V$ & 11.77 & 12.04 & 9.50 & low, & sparse information on \\
\hline$V$ & 10.85 & 16.18 & 14.48 & $\begin{array}{l}\text { in general } \\
<150\end{array}$ & $\begin{array}{l}\text { surface structure for } \\
\text { classes III-VI }\end{array}$ \\
\hline$V I$ & 13.14 & 7.81 & 10.00 & & \\
\hline VII & 14.41 & 9.55 & 7.59 & variable $^{2}$ & $\begin{array}{l}\text { transition zone from } \\
\text { katabatic wind to high } \\
\text { plateau regions }\end{array}$ \\
\hline VIII & 9.74 & 11.45 & 8.37 & variable $^{2}$ & $\begin{array}{l}\text { wind erosion, and } \\
\text { redistributional surface, } \\
\text { large sastrugi }\end{array}$ \\
\hline$I X$ & 5.10 & 6.70 & 4.82 & variable $^{2}$ & $\begin{array}{l}\text { wind glazed surfaces, } \\
\text { sastrugi, irregular layering }\end{array}$ \\
\hline$X$ & 8.70 & 9.46 & 8.56 & $\begin{array}{l}\text { very high } \\
\text { in general } \\
>200\end{array}$ & $\begin{array}{l}\text { small grains, homogenous } \\
\text { snowpack }\end{array}$ \\
\hline
\end{tabular}

${ }^{1}$ area common to Escat; ${ }^{2}$ due to persistent katabatic winds

for both sensors. The best agreement in classification is reached in three cases: 1) high accumulation areas within the dry snow zone covered by class X (in common: $57.9 \%$ ); 2) areas with reduced penetration depth due to effective near surfaces scatterers, i.e., regions affected by summer melt (class I with 51.8\% common pixels); and 3) areas with significantly increased FA due to the preferential alignment of surface roughness features (sastrugi) caused by persistent katabatic air flow (enclosed by classes VIII and IX-in common: $40.4 \%$ and $44.8 \%$, respectively). A short description of typical surface properties for all classes is provided in Table III. However, such specifications are limited, since the transition from one surface type to another is smooth, and the spectrum of possible physical characteristics is large even within one class. Furthermore, available information is still insufficient for some classes.

Regions exhibiting extreme values in one or more of our input parameters stand out clearly at both frequencies. The percolation zone is represented by class I, which is marked by a bright band of very high $\sigma_{\text {mean }}^{0}$ at the margins of the continent, where the effects of rapid grain growth [17] and formation of ice lenses and pipes during the summer months combine to form strong scattering layers [8], [23], [42]. Examples are the Amery Ice Shelf $\left(72^{\circ} \mathrm{E}\right)$ and the Larsen Ice Shelf on the Eastern coast of the Antarctic Peninsula $\left(64^{\circ} \mathrm{W}\right)$, or several smaller ice shelf areas aligned along the DML coast. Small FA illustrates the isotropic scattering of this surface type. In addition frequency differences in $\sigma_{\text {mean }}^{0}$ are small, suggesting that the penetration depth is similar for both frequencies. Hence the scattering is dominated by an upper surface layer.

Also class II is evolving from high backscattering together with low FA and smooth IG. Here, Nscat $\sigma_{\text {mean }}^{0}$ reaches its ex-

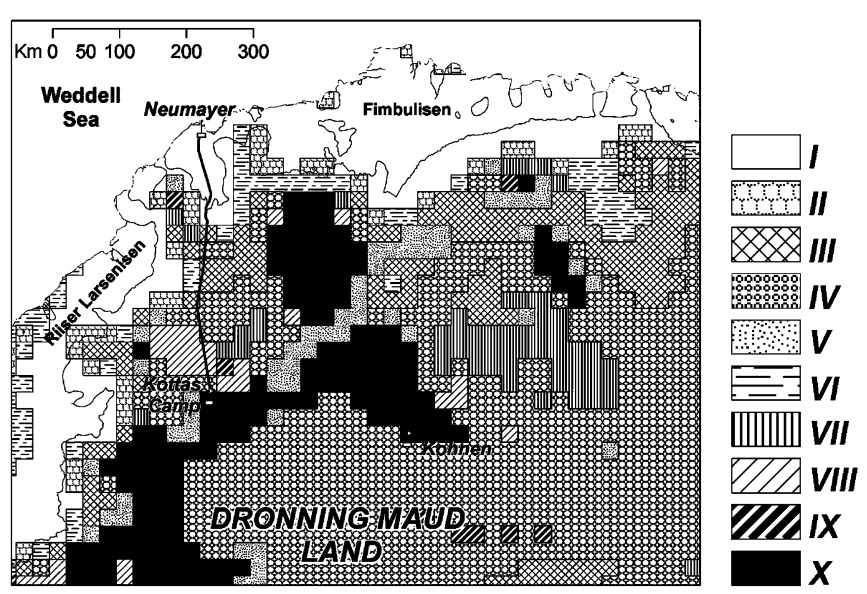

Fig. 10. Escat MLH classification result for DML study region.

tremes of up to $0.5 \mathrm{~dB}$, whereas Escat values are on the average $3 \mathrm{~dB}$ smaller than in the coastal area. Larger areas falling into class II are stretching from Victoria Land $\left(160^{\circ} \mathrm{E}\right)$ up to the high plateau at $100^{\circ} \mathrm{E}$, as well as starting on the Ross Ice Shelf up the slope toward the Rockefeller Plateau. Smaller areas are scattered on the high-elevation plateau of DML south of $79^{\circ}$. Class II is restricted to regions exhibiting very low accumulation rates of generally less then $100 \mathrm{~kg} \cdot \mathrm{m}^{-2} \cdot \mathrm{a}^{-1}$ down to $5 \mathrm{~kg} \cdot \mathrm{m}^{-2} \cdot \mathrm{a}^{-1}$ [4], [14], [51] associated with a dominance of coarse to very coarse snow grains, including the development of depth hoar. The steady increase in C-band backscattering observed toward the crest of the ice sheet was attributed to increased stratification of the snow pack by [42], as a result of decreasing accumulation rates and development of wind crusts. This assumption is confirmed by traverse studies [45] that found the number of strata within the upper $2 \mathrm{~m}$ to reach up to 60 , with an average of 35 . These findings compare with observations from central Greenland, where increased backscattering was also associated with intensified layering together with increased grain sizes due to low accumulation rates [11], [23]. Class I and II cluster means are not very distinct for Nscat and thus could not be correctly discriminated on the plateau area. The imaging geometry of Escat does not allow further mapping of this snow pack type.

In opposite, for the dry snow zone high accumulation rates can be linked to a compact firn-pack morphology with small grain sizes [7], [15], for which the penetration depth was described to be in the order of a few hundred times the wavelength [3]. Here the backscattering is only weak. Therefore, darker colors within the $\sigma_{\text {mean }}^{0}$ parameter images [Fig. 4(a)] indicate regions of high accumulation and are mapped by class $\mathrm{X}$, which is in addition characterized by an increased IG, confirming statements of [42] for a higher penetration depth. The largest connected areas of this kind are found in West Antarctica, i.e., Marie Byrd Land $\left(100^{\circ}-140^{\circ} \mathrm{W}\right)$, Ellsworth Land $\left(80^{\circ}\right.$ to $\left.100^{\circ} \mathrm{W}\right)$, and Palmer Land $\left(65^{\circ} \mathrm{W}\right)$. In agreement for both frequencies, the lowest values of $\sigma_{\text {mean }}^{0}$ (Escat $-22.5 \mathrm{~dB} / \mathrm{Nscat}$ $-17.4 \mathrm{~dB}$ ) are observed in Marie Byrd Land at two locations within the Executive Committee Range between $76^{\circ} 30^{\prime} \mathrm{S}$ and $77^{\circ} \mathrm{S}$ at $121^{\circ} \mathrm{W}$ and $132^{\circ} \mathrm{W}$, where an accumulation maximum of $560 \mathrm{~kg} \cdot \mathrm{m}^{-2} \cdot \mathrm{a}^{-1}$ has been reported by [29]. Scattered areas are found in DML, where values of up to $593 \mathrm{~kg} \cdot \mathrm{m}^{-2} \cdot \mathrm{a}^{-1}$ 


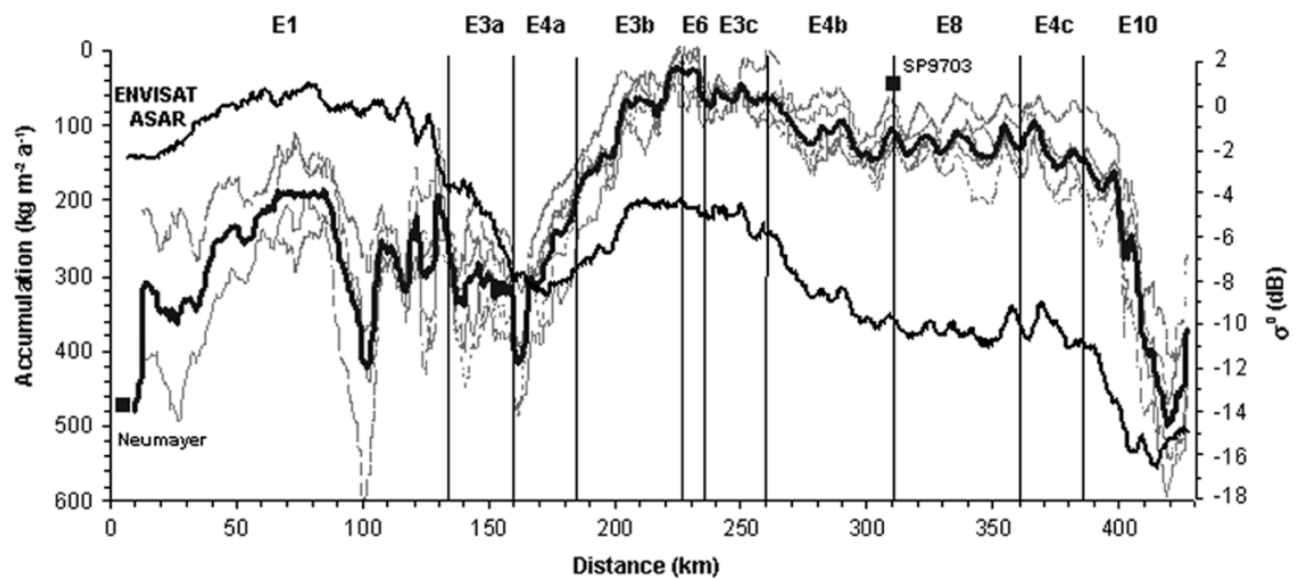

Fig. 11. Average net snow accumulation derived from stake readings along the Kottas Traverse route for the time period 1997-2001 (annual variability in gray), inversely plotted against ASAR wideswath $\sigma^{0}$ measurements (100-m pixel spacing) from March 2004 normalized to $35^{\circ}$ incidence. Squares mark the locations of snow pits described in the text. The transect is subdivided into sections that correspond to the Escat-derived snow pack classes with labels on top.

have been measured by stake line readings in the year 2001 near the Heimefrontfjella mountain range $\left(74^{\circ} 23^{\prime} \mathrm{S} / 9^{\circ} 22^{\prime} \mathrm{W}\right)$.

In east Antarctica striking patterns are generated by regions of strong katabatic air flow, which causes a higher surface roughness. They are represented by classes VII-IX, characterized by significantly increased values for FA. The dependence of this parameter on wind-generated features, i.e., sastrugi [26], [37] and snow dunes, is well known [16]. Stronger slope gradients account for a first-order azimuthal modulation of $\sigma_{\text {mean }}^{0}$ [3], as well as a steeper IG. Escat data generally exhibits a significantly higher variation of $\sigma^{0}$ with azimuth angle than observed for the Nscat data, which might partly be an artefact of the lower azimuth-angle coverage [see Fig. 2(b) and Fig. 3] and therefore reduced accuracy in deduction of FA. Regions with highest anisotropy are combined in class IX, namely Wilkes Land $\left(110^{\circ}\right.$ to $\left.130^{\circ} \mathrm{E}\right)$, Princess Elizabeth Land $\left(70^{\circ}\right.$ to $\left.90^{\circ}\right)$, and Terre Adélie $\left(130^{\circ}\right.$ to $\left.145^{\circ} \mathrm{E}\right)$, known for their high windspeeds near the margin of the ice sheet [34], [35], [37].

In east Antarctica, terrains on the coastal side of the ice divide exhibit strong variations in surface conditions. Here the classification algorithm produces a highly scattered small-scale pattern through all classes, especially for the Nscat data. No remarkable feature can be named from Mac Robertson Land $\left(60^{\circ}-80^{\circ} \mathrm{E}\right)$, over Kemb Land to Enderby Land $\left(60-40^{\circ} \mathrm{E}\right)$. For DML (Fig. 10) our classification results differ between both sensors concerning the exact pixel location of a certain surface class only. This region is known for its high spatial variability in surface conditions, due to changes in local weather conditions, changing winds and accumulation rates [32], [39], governed by orographic effects and surface undulations. For this, sample region ground truth data are available, crossing from the coastal percolation zone to the dry snow zone on the polar plateau. With these we can link our snow pack classes derived from satellite measurements and address uncertainties regarding their morphological differences.

\section{Determining Accumulation Rates Via SAR}

\section{A. Transect Neumayer-Kottas}

Annual stake readings covering a five-year period from 1997 to 2001 provide detailed information on mass balance along

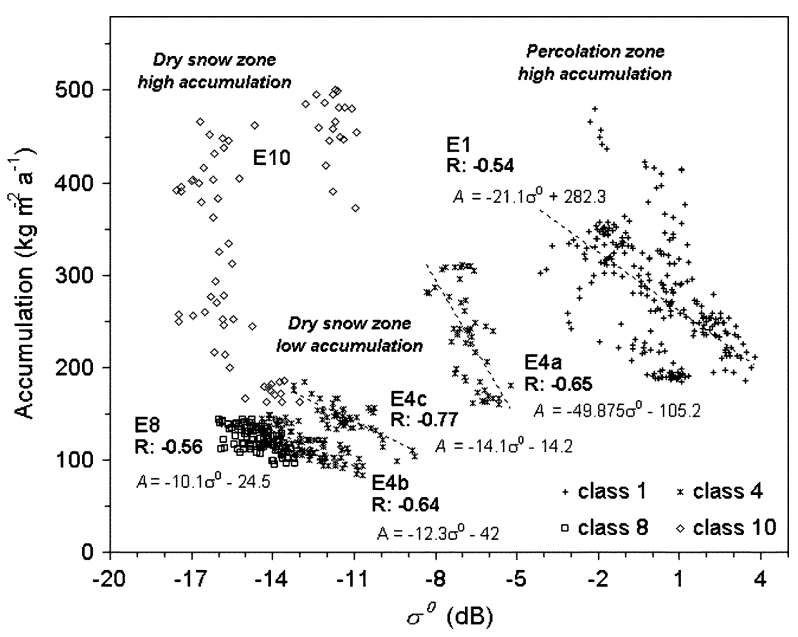

Fig. 12. Scatterplot of ASAR $\sigma^{0}$ values versus stake line net accumulation rates. Clusters correspond to the Escat-derived snow pack classes (also Fig. 11).

a continuous profile line connecting the German station Neumayer, situated near the edge of the Ekström Ice Shelf, with the Kottas camp nearby the Heimefrontfjella mountain range. Traceable in Fig. 11 is the typical trend of decreasing snow accumulation with increasing elevation (also Fig. 7) and distance to the coast, described in further detail in [39]. Undulations appear on a kilometer scale. Though a stronger interannual variability is recognizable, the general sequence of net accumulation rates along the transect is preserved over the years. A section of extraordinary strong variations can be observed between 90-170 $\mathrm{km}$ along the lower slope of the ice rise from the grounded coastal areas, probably due to increases in katabatic wind. Interestingly, years of above mean accumulation $(1997,1999,2001)$ alternate with years of below mean accumulation $(1998,2000)$, with strongest amplitudes on the ice shelf in direct neighborhood to the grounding line at a distance of $100 \mathrm{~km}$ from Neumayer station. Here, during the observation period, a maximum of $600 \mathrm{~kg} \cdot \mathrm{m}^{-2} \cdot \mathrm{a}^{-1}$ (1999) contrasts sharply with a minimum value of only $273 \mathrm{~kg} \cdot \mathrm{m}^{-2} \cdot \mathrm{a}^{-1}$ in the following year, giving an indication for the high temporal variability of snow accumulation within this region. Within a section of lowest accumulation along the stake line $(225-233 \mathrm{~km})$ the situation is reversed. 
(a)

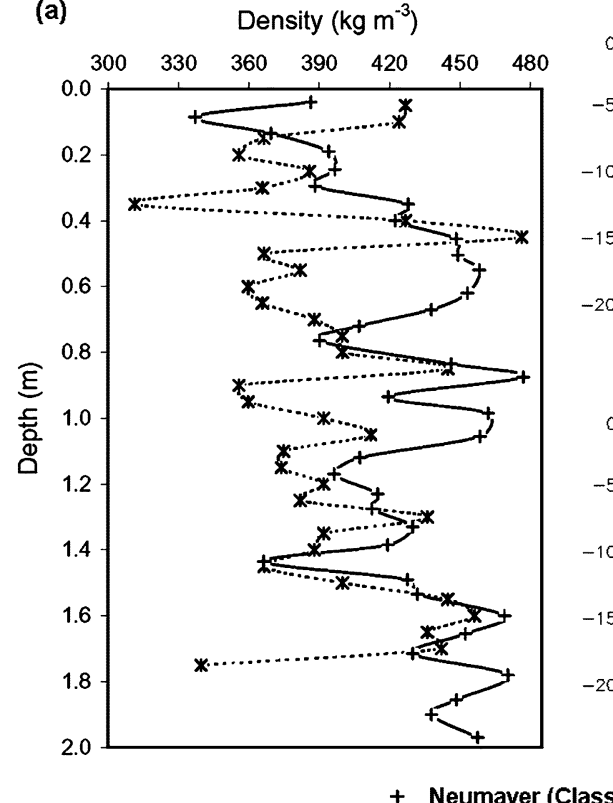

(b)

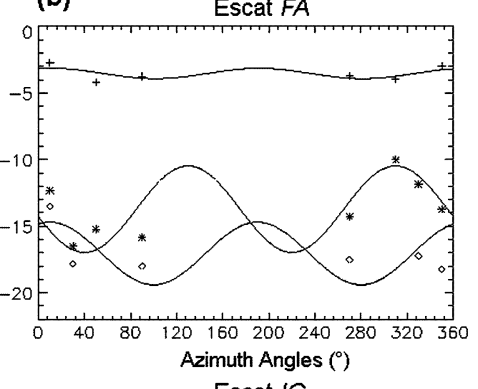

Escat IG

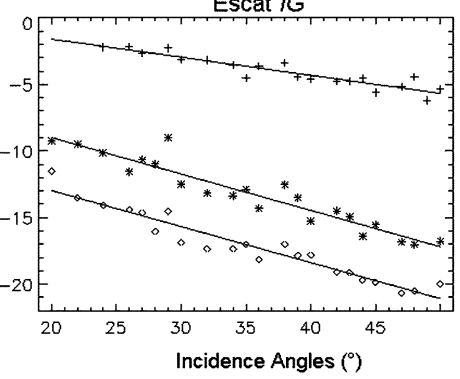

* SP9703 (Class iV) (c) Nscat FA

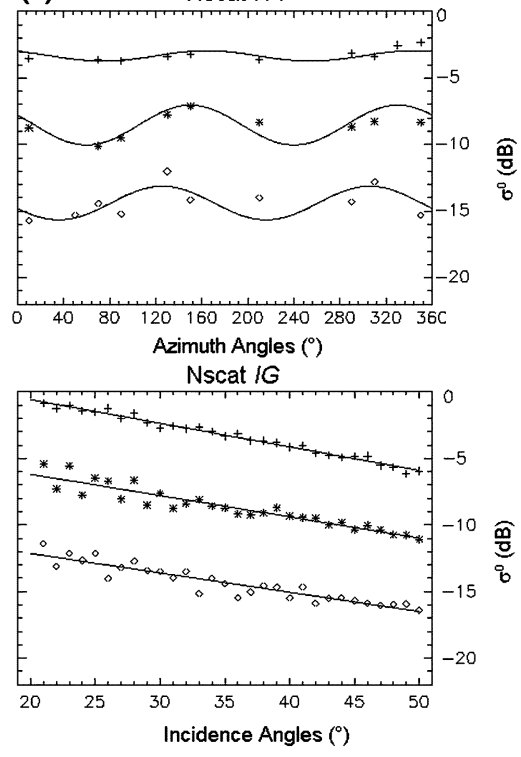

$\diamond$ Class $\mathrm{X}$

Fig. 13. (a) Depth-density profiles for two snow pits, located along Kottas Traverse route and corresponding (b) Escat and (c) Nscat scatterometer signatures FA (on top) and IG (on bottom).

While during 1999 ablation is observed $\left(-7 \mathrm{~kg} \cdot \mathrm{m}^{-2} \cdot \mathrm{a}^{-1}\right)$, a record of $84 \mathrm{~kg} \cdot \mathrm{m}^{-2} \cdot \mathrm{a}^{-1}$ is reached in the year 2000, emphasizing the role of snow redistribution by wind, which modifies the original precipitation pattern and causes a coincidental chronology of annual net mass-balance rates for a certain location along a profile. In the Kottas mountains at the end of the stake line, the local terrain and wind field generate a sudden rise in net snow accumulation, reaching average values up to $500 \mathrm{~kg}$. $\mathrm{m}^{-2} \mathrm{a}^{-1}$.

A varying snow accumulation can be related with changes in snow pack properties, in particular the annual layer thickness, grain size, and hence density-depth distribution. As observed earlier by Antarctic and Greenland ice sheet studies [3], [8], [11], [23], [30], [54], such changes are mirrored by the corresponding backscattering signatures, which show a clear rise in $\sigma^{0}$ with decreasing snow accumulation. Larger grain sizes and a higher number of strata per depth unit are thought to cause an increased volume scattering, accompanied with a reduction of penetration depth. Comparing the average snow accumulation rate along the Neumayer-Kottas camp stake line with our normalized ASAR data we also observe a remarkable reciprocal relationship between both datasets. Both curves progress in the same directions, when accumulation measurements are plotted inversely against the radar coefficient $\sigma^{0}$ (in decibels) as shown in Fig. 11.

When looking at the correlation factors, the percolation zone (R: -0.55), with well-developed scattering layers near the surface, must be separated from the dry snow zone with R: -0.74 . The crossover between those snow facies is roughly marked by the border between the Escat-derived classes III and IV ( $\mathrm{km} \mathrm{160)}$ at an elevation of around $650 \mathrm{~m}$ a.s.l.. Going more into the detail, we studied the relationship of accumulation and backscattering within our Escat-derived snowpack classes separately as illustrated in Fig. 12. Distinct clusters form here according to differences in snow morphology. For those classes which exhibit a good correlation between radar backscattering and surface net balance, we established simple linear regression functions to parameterise the accumulation. Class I, representing the flat Ekström Ice Shelf, separates as an agglomeration of rather scattered points on the right side, exhibiting a correlation factor $\mathrm{R}$ of -0.54 . Within this area $\sigma^{0}$ is generally higher than within the dry snow zone, regardless of snow accumulation rate. Snow pit studies at several points along our stake line reveal the snow packs typical stratigraphic layering and density distribution with depth, of which examples are presented in Fig. 13(a). Near Neumayer station there is evidence that high summer temperatures alter the snow pack in a way that contributes to stronger backscattering response. The snow was described as coarse-grained material, containing a series of up to 2-cm-thick ice lenses, starting at a distance of only a few centimeters from the surface. A mean density of $420 \mathrm{~kg} \cdot \mathrm{m}^{-3}$ was found within the snow pack's upper $2 \mathrm{~m}$.

In contrast, for class $\mathrm{X}$ which is in the sphere of influence of the Heimefrontfjella mountain range, the lowest values of $\sigma^{0}$ are recorded, although accumulation rates are comparably high. For this region, no correlation between both datasets was observed, since local effects cause spatially highly variable snow deposition and hence snow pack conditions, which cannot be resolved in the classification procedure by scatterometer data. No density distribution is available for this surface type, but the snow pack is described as consisting mainly of loose, homogenous, fined grained ( $<1$ to $2 \mathrm{~mm}$ ) snow crystals. Only one thin layer of consolidated material was found within the upper $1.5 \mathrm{~m}$ at a depth of $1 \mathrm{~m}$.

The highest correlation of up to -0.77 was found for lower accumulation areas within the dry snow zone, covered by spatially separated sections of class IV. The different alignment of surface roughness features toward north (simulated sensor look direction) induces a parallel shift along the $\sigma^{0}$ axis from section E4b to E4c in Fig. 12. Our findings are consistent with a previous study [11], which found backscattering to be generally more sensitive to changes in accumulation when the accumu- 
TABLE IV

REGRESSION COEFFICIENTS BETWEEN ACCUMULATION RATE $A$ AND BACKSCATTERING COEFFICIENT $\sigma^{0}$ [SEE (4)] FOR SECTIONS OF Class 4

\begin{tabular}{llll|llc}
\hline \hline & $\boldsymbol{a}$ & $\boldsymbol{b}$ & $\boldsymbol{R}$ & $\boldsymbol{a}^{\prime}$ & $\boldsymbol{b}^{\prime}$ & $\boldsymbol{R}^{\prime}$ \\
Kottas & -14.1 & -14.2 & -0.77 & - & - & - \\
Kohnen & & & & & & \\
S1 $(0-48.5 \mathrm{~km})$ & -6.53 & -45.3 & -0.88 & -7.5 & -61.3 & -0.92 \\
S2 $(48.5-87 \mathrm{~km})$ & -3.76 & -1.0 & -0.77 & -4.4 & -13.7 & -0.82 \\
S3 $(87-320 \mathrm{~km})$ & -0.73 & 49.4 & -0.24 & -2.3 & 23.6 & -0.52 \\
\hline \hline
\end{tabular}

lation rate is low $\left(100-250 \mathrm{~kg} \cdot \mathrm{m}^{-2} \cdot \mathrm{a}^{-1}\right)$. The correlation becomes highest for regions with little slope and smooth topography. Snow pit SP9703 (elevation: $1250 \mathrm{~m}$ a.s.l.) reveals for this snow pack type a series of alternating high-density layers of fine grains and lower density, coarse-grained firn, caused by annual and seasonal varying wind and temperature conditions. Additionally a number of seven wind crusts of less than $1 \mathrm{~mm}$ thickness are found at several depths over the upper $2 \mathrm{~m}$ of the snow pack. The average density is $390 \mathrm{~kg} \cdot \mathrm{m}^{-3}$, significantly lower than within the percolation zone.

The corresponding scatterometer-derived values for FA and IG [Fig. 13(b) and (c)] show for class I very little anisotropy and a flat decrease of $\sigma^{0}$ versus incidence angle, i.e., small IG, linked to a high backscattering level of up to $0 \mathrm{~dB}$. Within the dry snow zone (classes IV and $\mathrm{X}$ ) we find the backscattering reduced with a significant change in IG only for the Escat data. FA is high for both sensors, with larger amplitudes in C-band.

\section{B. Transect Kohnen}

A second area arranged to class IV using Escat and Nscat data, is situated on the Wegenerinlandeis plateau around Kohnen station. For this region a transect of ground truth data obtained by IPR is available for comparison with ASAR data. In order to reduce noise both datasets have been smoothed using a $2-\mathrm{km}$ running mean. In spite of similar backscattering characteristics, we find altered parameterizations between ground truth accumulation rates and ASAR measurements according to

$$
A=a \sigma^{0}+b .
$$

Our transect of 320-km length can be subdivided into three sections using a scatterplot of accumulation versus ASAR $\sigma^{0}$ similar to Fig. 12. For these we find coefficients $a$ and $b$ as listed in Table IV. Here we compare our results with subdivision E4c along the lower elevation Neumayer-Kottas traverse, which exhibits comparable topographical conditions and slope $(1.6 \mathrm{~m}$. $\left.\mathrm{km}^{-1}\right)$. Again we find a clear inverse response of backscattering to changes in accumulation rate. Furthermore we notice a trend of increasing backscattering with elevation [Fig. 14(a)]. This cannot be caused by accumulation changes, which exhibit irregular variations but show no certain tendency along the entire transect according to ground data [Fig. 14(b)]. Removing this trend from our satellite data and adjusting the regression coefficients to $a^{\prime}$ and $b^{\prime}$, we can improve the correlation coefficients $\left(R^{\prime}\right)$ between ASAR data and accumulation, especially for the third section $(87-320 \mathrm{~km})$.

Backscattering has also been linked to the mean annual air temperature [11], [30], for which elevation can serve as a proxy. Introducing the elevation $H$ as a second parameter additional

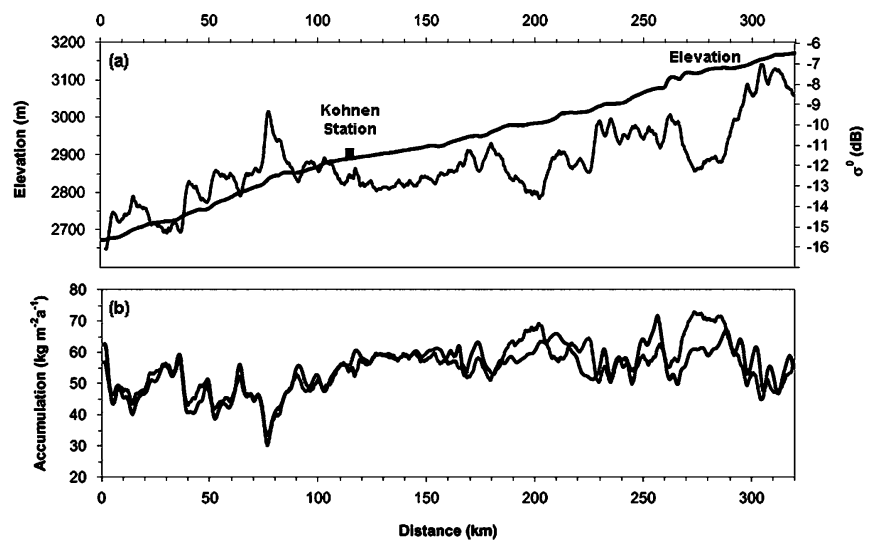

Fig. 14. (a) Elevation and ASAR $\sigma^{0}$ (on a 250-m grid) normalized to an overall incidence angle of $35^{\circ}$ and $0^{\circ}$ azimuth angle along the IPR route, and (b) IPR-derived accumulation data (gray line) [41] compared to accumulation estimations based on ASAR data (black line).

to the radar backscattering coefficient for performing a multivariate regression analysis, we yield good accumulation estimates based on

$$
A=-6 \sigma^{0}+0.088 H-275 .
$$

Our accumulation calculations resulting from ASAR and elevation data compare well with surface-mass-balance rates derived by IPR. Both curves progress parallel, with an average difference of $\pm 6.4 \%$. The accuracy of IPR data has been estimated to be within $5 \%$ to $10 \%$ (personal communication Dr. Olaf Eisen). The maximum disagreement is $-13.74 \mathrm{~kg} \cdot \mathrm{m}^{-2}$. $\mathrm{a}^{-1}(21.73 \%)$ occurring at $302 \mathrm{~km}$. This close approach is surprising, considering the difference in spatial resolution between IPR and our satellite data. The latter corresponds to an integration of backscattering responses over an area of $250 \times 250 \mathrm{~m}^{2}$.

The accuracy is higher as long as the transect is running parallel to satellite swath (up to $150 \mathrm{~km}$ from starting point). Therefore, differences within the second part of our profile line might partly result from an incomplete incidence angle normalization. The latter introduces an error of up to $1 \mathrm{~dB}$ for incidence-angle corrections being in the order of $10^{\circ}$ along the transect (see Section II-B), which corresponds to an accumulation error of about $6 \mathrm{~kg} \cdot \mathrm{m}^{-2} \cdot \mathrm{a}^{-1}$ according to (5) for a typical value of $\sigma^{0}$ along the transect. Another source of discrepancies are differences in temporal resolution between both datasets. Our IPR data cover a time span of about 185 years, based on an isochrone at an average depth of $25 \mathrm{~m}$ [41]. This corresponds roughly to the penetration depth of C-band in polar firn [42]. Thus, the volume contributing to the backscattering theoretically covers a comparable time span, but can easily vary due to effective scattering layers near the surface, e.g., caused by depth hoar. Such changes in penetration depth and therefore backscattering strength might be the reason for significant divergences of ground-truth and calculated accumulation-profile lines, e.g., occurring between $180-230 \mathrm{~km}$ or around $280 \mathrm{~km}$ from starting point. Since exact information on real penetration depth are not available, such estimates based on radar data must always be taken with care.

\section{SAR-Based Accumulation Map}

Based on (5), we calculated the spatial pattern of accumulation at a horizontal resolution of $250 \mathrm{~m}$ for an area as large 


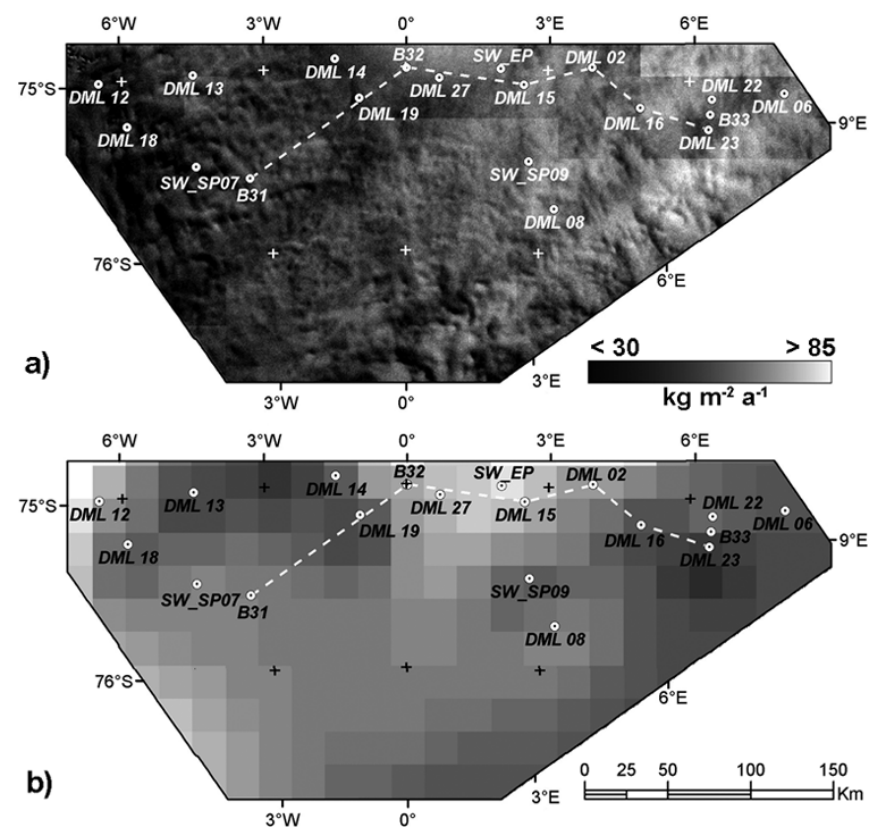

Fig. 15. Accumulation maps based on (a) SAR data and (b) interpolation from point records [18]. Firn core B32 is situated $1.6 \mathrm{~km}$ west of Kohnen station.

TABLE V

MEASURED $\left(A_{\mathrm{PT}}\right)$ Versus SAR-DERIVED ACCUMULATION $\left(A_{\mathrm{SAR}}\right)$ IN KIlograms PER SQUARE METER PER YEAR ON AMUNDSENISEN PlateAU

\begin{tabular}{lccccccc}
\hline \hline Name & Lon & Lat & $\begin{array}{c}\text { Time } \\
\text { Period }\end{array}$ & $\begin{array}{c}\text { Time } \\
\text { Span }\end{array}$ & $\boldsymbol{A}_{\text {pt }}$ & $\boldsymbol{A}_{\text {SAR }}$ & $\begin{array}{c}\text { Diff. } \\
{[\%]}\end{array}$ \\
\hline B31 & $03^{\circ} 26^{\prime} \mathrm{W}$ & $75^{\circ} 35^{\prime} \mathrm{S}$ & $1801-1997$ & 196 & 59 & 55 & -7.2 \\
$\mathrm{B32}$ & $00^{\circ} 01^{\prime} \mathrm{E}$ & $75^{\circ} 00^{\prime} \mathrm{S}$ & $1816-1997$ & 181 & 62 & 55 & -11.1 \\
$\mathrm{~B} 33$ & $06^{\circ} 30^{\prime} \mathrm{E}$ & $75^{\circ} 10^{\prime} \mathrm{S}$ & $1801-1997$ & 196 & 47 & 55 & 16.5 \\
DML 02 & $03^{\circ} 55^{\prime} \mathrm{E}$ & $74^{\circ} 58^{\prime} \mathrm{S}$ & $1919-1995$ & 76 & 57 & 52 & -9.0 \\
DML 06 & $08^{\circ} 01^{\prime} \mathrm{E}$ & $75^{\circ} 00^{\prime} \mathrm{S}$ & $1899-1996$ & 97 & 50 & 66 & 31.0 \\
DML 08 & $03^{\circ} 17^{\prime} \mathrm{E}$ & $75^{\circ} 45^{\prime} \mathrm{S}$ & $1819-1996$ & 77 & 60 & 67 & 12.3 \\
DML 12 & $06^{\circ} 30^{\prime} \mathrm{W}$ & $75^{\circ} 00^{\prime} \mathrm{S}$ & $1816-1998$ & 182 & 62 & 35 & -42.7 \\
DML 13 & $04^{\circ} 30^{\prime} \mathrm{W}$ & $75^{\circ} 00^{\prime} \mathrm{S}$ & $1800-1997$ & 197 & 47 & 45 & -5.1 \\
DML 14 & $01^{\circ} 30^{\prime} \mathrm{W}$ & $74^{\circ} 57^{\prime} \mathrm{S}$ & $1801-1997$ & 196 & 53 & 38 & -28.0 \\
DML 15 & $02^{\circ} 30^{\prime} \mathrm{E}$ & $75^{\circ} 05^{\prime} \mathrm{S}$ & $1801-1997$ & 196 & 64 & 65 & 1.0 \\
DML 16 & $05^{\circ} 00^{\prime} \mathrm{E}$ & $75^{\circ} 10^{\prime} \mathrm{S}$ & $1816-1997$ & 181 & 48 & 62 & 28.4 \\
DML 18 & $06^{\circ} 00^{\prime} \mathrm{W}$ & $75^{\circ} 15^{\prime} \mathrm{S}$ & $1801-1997$ & 196 & 50 & 41 & -19.0 \\
DML 19 & $01^{\prime} 00^{\prime} \mathrm{W}$ & $75^{\circ} 10^{\prime} \mathrm{S}$ & $1810-1997$ & 187 & 44 & 39 & -11.9 \\
DML 22 & $06^{\prime} 30^{\prime} \mathrm{E}$ & $75^{\circ} 05^{\prime} \mathrm{S}$ & $1801-1997$ & 196 & 58 & 64 & 10.2 \\
DML 23 & $06^{\circ} 30 \mathrm{E}$ & $75^{\circ} 15^{\prime} \mathrm{S}$ & $1816-1997$ & 181 & 38 & 50 & 30.4 \\
DML 27 & $00^{\circ} 42^{\prime} \mathrm{E}$ & $75^{\circ} 03^{\prime} \mathrm{S}$ & $1935-1999$ & 64 & 68 & 53 & -22.0 \\
SW_07 & $04^{\circ} 35^{\prime} \mathrm{W}$ & $75^{\circ} 30^{\prime} \mathrm{S}$ & $1982-1993$ & 11 & 60 & 38 & -37.5 \\
SW_09 & $02^{\circ} 41^{\prime} \mathrm{E}$ & $75^{\circ} 30^{\prime} \mathrm{S}$ & $1980-1993$ & 13 & 50 & 61 & 22.4 \\
SW_EP ${ }^{1}$ & $02^{\circ} 00^{\prime} \mathrm{E}$ & $75^{\circ} 00^{\prime} \mathrm{S}$ & $1865-1991$ & 126 & 77 & 64 & -16.5 \\
\hline
\end{tabular}

' obtained by SWEDARP - Swedish Antarctic Research Program

as $70 \times 10^{3} \mathrm{~km}^{2}$ surrounding our IPR transect [Fig. 15(a)] and being included in class IV. In order to assess the accuracy of our product we judge the accumulation obtained from SAR at locations for which independent field measurements are available (Table V). These data were mainly derived from shallow firn cores, many of which go back more than 180 years, thus covering a time span comparable to our IPR data. The difference between ground truth records and SAR-derived accumulation rates varies on average by $19 \%$, ranging from $-42.7 \%$ to $31 \%$. The accuracy is found to be nonsystematic and irrespective of both (1) the distance between point accumulation measurements and IPR transect (used for calibrating the SAR signals), as well as (2) the accumulation time span that is covered by firn and snow pit samples. The same sources of discrepancies apply as mentioned above for the transect Kohnen including the accuracy of field measurements, which we cannot quantify.

The same field records were used to interpolate an accumulation grid at 20-km resolution [18] with which we compare our SAR-derived accumulation map. This low-resolution dataset has until now been the best source of information for ice-sheet modeling within this region. We find that with use of SAR data not only small-scale accumulation variations are now visible, but also a significantly different accumulation pattern is revealed. While in Fig. 15(a) a clear increase in accumulation can be observed toward the east of our study area, the situation seems to be reversed in Fig. 15(b). In total the accumulation sums up to $3.67 \mathrm{Gt} \cdot \mathrm{a}^{-1}$ versus $4.4 \mathrm{Gt} \cdot \mathrm{a}^{-1}$ from [18], corresponding to a difference of $20 \%$. This result gives an indication for the present uncertainties in quantification of ice-sheet mass balance.

\section{SUMmary}

This paper combines satellite-borne radar data with ground truth mass-balance information derived by annual stake line readings, firn cores, and geophysical field surveys carried out by IPR. Our aim was to study the spatial distribution of different snow pack regimes over the Antarctic ice sheet and assess surface-mass-balance variations, in particular throughout the DML region. We used Escat and Nscat data in order to identify regions with similar backscattering behavior by three parameters $\left(\sigma_{\text {mean }}^{0}\right.$ azimuth and incidence angle dependence of backscattering FA and IG), which are similarly mapped by both C-band and Ku-band sensor types. Thus, by applying a maximum-likelihood classification we produce comparable results, showing that despite a limited imaging geometry also Escat is a useful tool to carry out snow pack studies. Distinctions depending on frequency can be explained largely by differences in penetration depth and therefore in the volume contributing to the backscattering as well as by differences in scattering mechanisms at internal interfaces and grains. Related to this fact is that single frequencies may be responding to different periods in recent snow-accumulation history, which was however not examined in this study.

The scatterometer-derived parameters IG and FA were also used to normalize Envisat ASAR wideswath data to unique incidence and azimuth angles for a test site in DML. Our studies confirm inverse correlations between ASAR backscattering and snow accumulation rates, which become strongest within low-accumulation dry snow zone areas. Our hypothesis, that within classes of similar backscattering behavior unique parameterizations can be established between accumulation rates and backscattering amplitude, can only be partly confirmed. Though we can delimit areas for which we find simple functions for estimating surface-mass-balance changes, the ability to transfer these from one region to another is limited. The reason for this is that beside the accumulation rate, further parameters which vary spatially in number and composition alter the snow-pack backscattering properties, such as the presence of small-scale surface roughness features or buried effective scattering layers, i.e., ice lenses, depth hoar, or wind crusts. Furthermore, the terrain is changing the local incidence 
angle in a way that is not taken into account by our scatterometer-derived normalization procedure. On the higher elevation plateau area of DML, a steadily decreasing mean annual air temperature with increasing elevation introduces a linear trend in $\sigma^{0}$, which overlays the irregular signal undulations caused by varying accumulation rates. Both observed signature responses are mostly controlled by grain-size variations [21].

For a test site in Dronning Maud Land we have derived the first high-resolution accumulation map based on SAR and ground truth data. Even in this area with a comparably dense network of ground measurements, the spatial characteristics and the magnitude of accumulation differs significantly from previous interpolations of accumulation point measurements. This suggests that accumulation compilations from single point records can be misleading if their area of validity is left unconsidered.

\section{CONCLUSION}

SAR measurements can be utilized to map surface mass balance, most suitably within lower accumulation areas of the dry snow zone. However, the relationship between accumulation rate and backscattering is not unique over the entire spectrum of possible Antarctic snow pack conditions. The mean annual air temperature, which is highly dependent on elevation is a parameter that must further be considered in this context. It is therefore obvious that parameterizations of accumulation rates via SAR data can be established only for areas of limited extent that can be defined using low-resolution scatterometer data. The inclusion of surface heights as a fourth parameter beside $\sigma_{\text {mean }}^{0} \mathrm{FA}$, and IG, for classifying Antarctic snow pack types might improve the discrimination of snow regimes that exhibit similar backscattering characteristics, in spite of different snow morphology.

A strong advantage of SAR-derived accumulation estimates at high resolution is the ability to distinguish climatically caused accumulation changes from those related to small-scale surface undulations upstream of a drilling site. This is of great relevance for the climatic interpretation of deep ice core records, such as obtained by the EPICA project. They could serve as well for validation of output from atmospheric numerical models. For regional calibration of radar signals, accurate ground truth data on accumulation are needed, preferably along continuous profiles lines. In this we see the major problem in application of our method.

However our findings are also useful by examining the surrounding backscattering pattern of accumulation point measurements. This would indicate the degree to which the latter can be considered to be representative on the regional scale, even if the spatial variability of snow accumulation cannot be quantified. With regard to $\mathrm{Ku}$-band, the detected small-scale variations in snow pack properties will be useful for the analysis of high-resolution radar altimeter data like from the forthcoming Cryosat mission.

\section{ACKNOWLEDGMENT}

SAR data were provided by the European Space Agency within the Cryosat Cal/Val AO. Scatterometer data were made available by the Physical Oceanography Distributed Active
Archive Center for Nscat, and by the French Processing and Archiving Facility (IFREMER) for Escat. The authors thank O. Eisen for providing mass-balance information by means of IPR data. Ground truth accumulation data for sites 07/09 and SW were provided by SWEDARP. The authors also thank two anonymous reviewers for valuable comments on the manuscript.

\section{REFERENCES}

[1] R. J. Arthern, D. J. Wingham, and A. L. Ridout, "Controls on ERS altimeter measurements over ice sheets: Footprint-scale topography, backscatter fluctuations, and the dependence of microwave penetration depth on satellite orientation," J. Geophys. Res., vol. 106, no. D24, pp. $33471-33$ 484, 2001.

[2] E. P. W. Attema, "The active microwave instrument on-board the ERS-1 satellite," Proc. IEEE, vol. 79, no. 6, pp. 791-799, Jun. 1991.

[3] A. W. Bingham and M. Drinkwater, "Recent changes in the microwave scattering properties of the Antarctic ice sheet," IEEE Trans. Geosci. Remote Sens., vol. 38, no. 4, pp. 1810-1820, Jul. 2000.

[4] D. H. Bromwich, "Snowfall in high southern latitudes," Rev. Geophys., vol. 26, no. 1, pp. 149-168, 1988 .

[5] J. C. Comiso, H. J. Zwally, and J. L. Saba, "Radiative transfer modeling of microwave emission and dependence on firn properties," Ann. Glaciol., vol. 3, pp. 54-58, 1982.

[6] C. H. Davis, C. A. Kluever, B. J. Haines, C. Perez, and Y. Yoon, "Improved elevation change measurement of the southern Greenland ice sheet from satellite radar altimetry," IEEE Trans. Geosci. Remote Sens., vol. 38, no. 3, pp. 1367-1378, May 2000.

[7] D. J. Drewry, S. R. Jordan, and E. Jankowski, "Measured properties of the Antartic ice sheet: Surface configuration, ice thickness, volume and bedrock characteristics," Ann. Glaciol., vol. 3, pp. 83-91, 1982.

[8] M. R. Drinkwater, D. G. Long, and A. W. Bingham, "Greenland snow accumulation estimates from satellite radar scatterometer data," J. Geophys. Res., vol. 106, no. D24, pp. 33 935-33 950, 2001.

[9] J. D. Flach, K. C. Partington, C. Ruiz, E. Jeansou, and M. R. Drinkwater, "Inversion of the surface properties of ice sheets from satellite microwave data," IEEE Trans. Geosci. Remote Sens., vol. 43, no. 4, pp. 743-752, Apr. 2005.

[10] D. Floricioiu and H. Rott, "Seasonal and short-term variability of multifrequency, polarimetric radar backscatter of Alpine terrain from SirC/X-SAR and AIRSAR data," IEEE Trans. Geosci. Remote Sens., vol. 39, no. 12, pp. 2634-2648, Dec. 2001.

[11] R. Forster, K. C. Jezek, J. Bolzan, F. Baumgartner, and S. P. Gogineni, "Relationships between radar backscatter and accumulation rates on the Greenland ice sheet," Int. J. Remote Sens., vol. 20, pp. 3131-3147, 1999.

[12] M. Frezzotti and O. Flora, "Ice dynamic features and climatic surface parameters in East Antarctica from Terra Nova Bay to Talos Dome and Dome C: ITASE Italian traverses," Terra Antartica, vol. 9, no. 1, pp. 47-54, 2002.

[13] A. K. Fung and K. S. Chen, "Dependence of the surface backscattering coefficients on roughness, frequency and polarization states," Int. J. Remote Sens., vol. 13, no. 9, pp. 1663-1680, 1992.

[14] M. B. Giovinetto and H. J. Zwally, "Spatial distribution of net surface accumulation on the Antarctic ice sheet," Ann. Glaciol., vol. 31, pp. $171-178,2000$

[15] I. D. Goodwin, "Ice sheet topography and surface characteristics in eastern Wilkes Land, east Antarctica," ANARE Res. Notes, vol. 64, 1988.

[16] I. D. Goodwin, "Snow-accumulation variability from seasonal surface observations and firn-core stratigraphy, eastern Wilkes Land, Antarctica," J. Glaciol., vol. 37, no. 127, pp. 383-387, 1991.

[17] J. Gow, "On the rates of growth of grains and crystals in south polar firn," J. Glaciol., vol. 8, no. 33, pp. 241-252, 1969.

[18] P. Huybrechts, D. Steinhage, F. Wilhelms, and J. Bamber, "Balance velocities and measured properties of the Antarctic ice sheet from a new compilation of gridded data for modeling," Ann. Glaciol., vol. 30, pp. 52-60, 2000.

[19] K. C. Jezek, P. Gogineni, and M. Shanableh, "Radar measurements of melt zones on the Greenland ice sheet," Geophys. Res. Lett., vol. 21, no. 1, pp. 33-36, 1994.

[20] J. C. King, P. S. Anderson, D. G. Vaughan, G. W. Mann, S. D. Mobbs, and S. B. Vosper, "Wind-borne redistribution of snow across an Antarctic ice rise," J. Geophys. Res., vol. 109, no. D11104, 2004. DOI: 10.1029/2003JD004361. 
[21] B. Legrésy and F. Rémy, "Using the temporal variability of satellite radar altimetric observations to map surface properties of the Antarctic ice sheet," J. Glaciol, vol. 44, no. 147, pp. 197-206, 1998.

[22] H. Liu, K. Jezek, B. Li, and Z. Zhao, "Radarsat Antarctic Mapping Project digital elevation model version 2," Nat. Snow Ice Center, Boulder, CO, 2001. Digital media.

[23] D. G. Long and M. R. Drinkwater, "Greenland ice-sheet surface properties observed by the seasat-A scatterometer at enhanced resolution," J. Glaciol., vol. 40, no. 135, pp. 213-230, 1994.

[24] D. G. Long and G. B. Skouson, "Calibration of spaceborne scatterometer data using tropical rainforests," IEEE Trans. Geosci. Remote Sens., vol. 34, no. 2, pp. 413-424, Mar. 1996.

[25] D. G. Long and M. R. Drinkwater, "Cryosphere applications of NSCAT data," IEEE Trans. Geosci. Remote Sens., vol. 37, no. 3, pp. 1671-1684, May 1999.

[26] _ _ "Azimuth variation in microwave scatterometer and radiometer data over Antarctica," IEEE Trans. Geosci. Remote Sens., vol. 38, no. 4, pp. 1857-1870, Jul. 2000.

[27] C. Mätzler, "Applications of the interaction of microwaves with the natural snow cover," Remote Sens. Rev., vol. 2, pp. 259-392, 1987.

[28] K. Melvold, J. O. Hagen, J. F. Pinglot, and N. Gundestrup, "Large spatial variation in accumulation rate in Jutulstraumen ice stream, Dronning Maud Land, Antarctica," Ann. Glaciol., vol. 27, pp. 231-238, 1998

[29] E. Mosley-Thompson, J. Dai, L. G. Thompson, P. M. Grootes, J. K. Arbogast, and J. F. Paskievitch, "Glaciological studies at siple station (Antarctica): Potential ice-core paleoclimatic record," J. Glaciol., vol. 37, no. 125 , pp. 11-22, 1991 .

[30] J. Munk, K. C. Jezek, R. R. Forster, and S. P. Gogineni, "An accumulation map for the Greenland dry-snow zone facies derived from spaceborne radar," J. Geophys. Res., vol. 108, no. D9, pp. ACL 8 1-12, 2003.

[31] N. A. Nereson, C. F. Raymond, R. W. Jacobel, and E. D. Waddington, "The accumulation pattern across Siple Dome, West Antarctica, inferred from radar-detected internal layers," J. Glaciol., vol. 46, no. 152, pp. $75-87,2000$.

[32] H. Oerter, F. Wilhelms, F. Jung-Rothenhäusler, F. Göktas, H. Miller, W. Graf, and S. Sommer, "Accumulation rates in dronning maud land as revealed by dielectric-profiling measurements of shallow firn cores," Ann. Glaciol., vol. 30, pp. 27-34, 2000.

[33] A. Pälli, J. C. Kohler, E. Isaksson, J. C. Moore, J. F. Pinglot, V. A. Pohjola, and H. Samuelsson, "Spatial and temporal variability of snow accumulation using ground-penetrating radar and ice cores on Svalbard glacier," J. Glaciol., vol. 48, no. 162, pp. 417-424, 2002.

[34] T. R. Parish, "Surface airflow over east Antarctica," Mon. Weath. Rev., vol. 110, pp. 84-90, 1982.

[35] T. R. Parish and D. H. Bromwich, "The surface windfield over the Antarctic ice sheet," Nature, vol. 328, pp. 51-54, 1987.

[36] W. Rack, "Streuverhalten und morphologie der Antarktischen schneedecke aus scatterometer-messungen von ERS-1," M.Sc. thesis, Univ. Innsbruck, Innsbruck, Austria, 1995.

[37] F. Rémy, M. Ledroit, and J. F. Minster, "Katabatic wind intensity and direction over Antarctica derived from scatterometer data," Geophys. Res. Lett., vol. 19, pp. 1021-1024, 1992.

[38] C. Richardson, E. Aarholt, S.-E. Hamram, P. Holmlund, and E. Isaksson, "Spatial distribution of snow in western Dronning Maud Land, East Antarctica, mapped by a ground-based snow radar," J. Geophys. Res., vol. 102, no. B9, pp. 20343-20 353, 1997.

[39] C. Richardson-Näslund, "Spatial characteristics of snow accumulation in Dronning Maud Land, Antarctica," Global Planetary Change, vol. 42, pp. 31-43, 2004

[40] E. Rignot and R. H. Thomas, "Mass balance of polar ice sheets," Science, vol. 297, pp. 502-506, 2002.

[41] G. Rotschky, O. Eisen, F. Wilhelms, U. Nixdorf, and H. Oerter, "Spatial distribution of surface mass balance on Amundsenisen plateau, Antarctica, derived from ice-penetrating radar studies," Ann. Glaciol., vol. 39, pp. 265-270, 2004.

[42] H. Rott, K. Sturm, and H. Miller, "Active and passive microwave signatures of Antarctic firn by means of field measurements and satellite data," Ann. Glaciol., vol. 17, pp. 337-343, 1993.

[43] H. Rott and W. Rack, "Characterization of Antarctic firn by means of ERS-1 scatterometer measurements," in Proc. IGARSS, vol. 3, Florence, Italy, Jul. 10-14, 1995, pp. 2041-2043. 1995.

[44] V. B. Spikes, G. S. Hamilton, S. A. Arcone, S. Kaspari, and P. Mayewski, "Variability in accumulation rates from GPR profiling on the West Antarctic plateau," Ann. Glaciol., vol. 39, pp. 238-244, 2004.

[45] S. Surdyk and M. Fily, "Comparison of the passive microwave spectral signature of the Antarctic ice sheet with ground traverse data," Ann. Glaciol., vol. 17, pp. 161-166, 1993.
[46] C. T. Swift, P. S. Hayes, J. S. Herd, W. L. Jones, and V. E. Delnore, "Airborne mircrowave measurements of the suthern Greenland ice sheet," $J$ Geophys. Res., vol. 90, pp. 1983-1994, 1985.

[47] R. Thomas, C. Davis, W. Krabill, and J. McConnell, "Greenland ice sheet elevation change since 1978 from radar and laser altimetry," Polar Geogr., vol. 23, no. 3, pp. 169-184, 1999.

[48] R. Thomas, B. Csatho, C. Davis, C. Kim, W. Krabill, S. Manizade, J. McConnell, and J. Sonntag, "Mass balance of higher-elevation parts of the Greenland ice sheet," J. Geophys. Res., vol. 106, no. D24, pp. 33 707-33 716, 2001.

[49] W. Tsai, J. E. Graf, C. Winn, J. N. Huddleston, S. Dunbar, M. H. Freilich, F. J. Wentz, D. G. Long, and W. Linwood Jones, "Postlaunch sensor verification and calibration of the NASA scatterometer," IEEE Trans. Geosci. Remote Sens., vol. 37, no. 3, pp. 1517-1542, May 1999.

[50] F. T. Ulaby, R. K. Moore, and A. K. Fung, Microwave Remote Sensing-Active and Passive. Reading, MA: Addison-Wesley, 1981, vol. 3.

[51] D. G. Vaughan, J. J. Bamber, M. B. Giovinetto, J. Russell, and A. P. R Cooper, "Reassessment of net surface mass balance in Antarctica," $J$ Clim., vol. 12, pp. 933-946, 1999.

[52] R. D. West, D. P. Winebrenner, and H. Rott, "Microwave emission from density-stratified Antarctic firn at $6 \mathrm{~cm}$ wavelength," J. Glaciol., vol. 42 , no. 140 , p. 63,1996

[53] D. J. Wingham, A. J. Ridout, R. Scharroo, R. Arthern, and C. K. Shum, "Antarctic elevation change from 1992 to 1996," Science, vol. 282, pp. 456-458, 1998.

[54] V. R. Wismann and K. Boehnke, "Monitoring snow properties on Greenland with ERS scatterometer and SAR," in Proc. 3rd ERS Symp. Space at the Service of Our Environment, 1997, ESA SP-414, pp. 857-862.

[55] H. J. Zwally and M. B. Giovinetto, "Accumulation in Antarctica and Greenland derived from passive-microwave data: A comparison with contoured compilations," Ann. Glaciol., vol. 21, pp. 123-130, 1995.

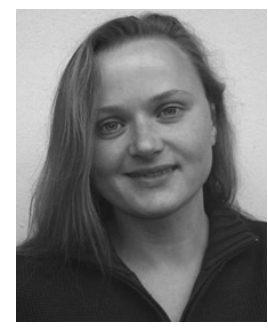

Gerit Rotschky was born in Hildburghausen, Germany, in 1975. She received the Diploma in geography from the Technical University of Dresden, Dresden, Germany, and the honor degree in geographical information systems from the Dr. Bush Innovative Education Center, Jena, Germany, in 2001 and 2002, respectively. She is currently pursuing the Ph.D. degree at the Alfred Wegener Institute for Polar and Marine Research, Bremerhaven, Germany.

From 1997 to 2000, she was a Student Assistant at the Faculty of Civil Engineering, Technical University of Dresden, Germany. Her research interests are microwave signatures of snow and ice in relation to mass-balance studies based on remote sensing images with emphasis on SAR and scatterometry. She participated in an expedition to Dronning Maud Land, Antarctica in the season 2003-2004.

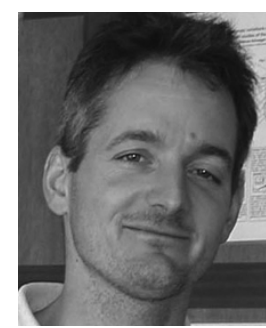

Wolfgang Rack (M'01) was born in Graz, Austria, in 1968. He received the M.Sc. degree in meteorology and the Ph.D. degree in glaciology from the University of Innsbruck, Innsbruck, Austria, in 1995 and 2000 , respectively.

Between 1995 and 2001, he was a Research Scientist at the Institute for Meteorology and Geophysics, University of Innsbruck. Since 2001, he has been a Research Scientist at Alfred Wegener Institute for Polar and Marine Research, Bremerhaven, Germany. His research interests are remote sensing studies of snow and ice with emphasis on SAR interferometry. He is currently involved in mass-balance studies in order to quantify the contribution of polar ice sheets to sea level rise. He actively contributed to several national and international projects on microwave signatures of snow, retreat, and break up of ice shelves, glacier mass balance, and alpine hydrology. He has participated in several scientific expeditions to Antarctica, the Arctic, and Patagonia. 
Wolfgang Dierking received the Diploma degree in geophysics from the University of Hamburg, Hamburg, Germany, and the Ph.D. degree in physics from the University of Bremen, Bremen, Germany, in 1985 and 1989, respectively. His Ph.D. project dealt with radar remote sensing of the ocean.

Between 1990 and 1993, he held a postdoc position at the Alfred Wegener Institute for Polar and Marine Research, Bremerhaven, Germany, where he worked on remote sensing of sea ice. From 1993 to 1995, he joined the Remote Sensing Group at Chalmers University of Technology, Göteborg, Sweden. During this period, he focused on ground-based radar measurements and microwave scatter modeling with applications to sea ice monitoring. From 1996 to 2002, he was an Associate Research Professor at the Department of Electromagnetic Systems, Technical University of Denmark. His work dealt with the utilization of polarimetric and interferometric SAR data in geoscientific studies. Since March 2002, he has been a Senior Scientist at AWI, working on remote sensing techniques used in climate research. He has participated in several land-based, ship-based, and airborne geoscientific field campaigns, among them a number of expeditions related to sea ice studies in the Arctic, Antarctic, and in the Baltic Sea. He is currently a member of the ESA SAR Advisory Group.

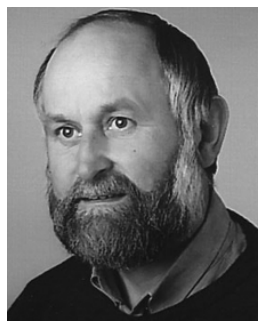

Hans Oerter was born in Nuremberg, Germany, in 1949. He received both the Diploma and Ph.D. degree in civil engineering from the Technical University of Munich, Munich, Germany, in 1975 and 1981, respectively.

Since 1988, he has been a Research Scientist at the Alfred Wegener Institute for Polar and Marine Research (AWI), Bremerhaven, Germany. He has over 20 years experience in field glaciology and ice core analysis on alpine glaciers, in Greenland and Antarctica. His research interests include stable isotope analysis of snow and ice samples and mass-balance studies for both the Greenland and the Antarctic ice sheet. Between 2001 and 2005, he was deputy leader of the section "Structure and Dynamics of the Lithosphere and Polar Ice Sheets" at AWI.

Dr. Oerter is one of the national representatives in the Standing Scientific Group of Physics of the Scientific Committee on Antarctic Research (SCAR) since 2002. 